\title{
Magnetic and Clast Fabrics as Measurements of Grain-Scale Processes Within the Death Valley Shallow Crustal Detachment Faults
}

\author{
Nicholas W. Hayman \\ Bernard A. Housen \\ Western Washington University, bernard.housen@wwu.edu \\ T. T. Cladouhos \\ K. Livi
}

Follow this and additional works at: https://cedar.wwu.edu/geology_facpubs

Part of the Geology Commons

\section{Recommended Citation}

Hayman, Nicholas W.; Housen, Bernard A.; Cladouhos, T. T.; and Livi, K., "Magnetic and Clast Fabrics as Measurements of GrainScale Processes Within the Death Valley Shallow Crustal Detachment Faults" (2004). Geology Faculty Publications. 13.

https://cedar.wwu.edu/geology_facpubs/13 


\title{
Magnetic and clast fabrics as measurements of grain-scale processes within the Death Valley shallow crustal detachment faults
}

\author{
Nicholas W. Hayman, ${ }^{1}$ B. A. Housen, ${ }^{2}$ T. T. Cladouhos, ${ }^{3,4}$ and K. Livi ${ }^{5}$ \\ Received 17 November 2003; revised 23 March 2004; accepted 21 April 2004; published 29 May 2004.
}

[1] The rock product of shallow-crustal faulting includes fine-grained breccia and clay-rich gouge. Many gouges and breccias have a fabric produced by distributed deformation. The orientation of fabric elements provides constraints on the kinematics of fault slip and is the structural record of intrafault strain not accommodated by planar and penetrative surfaces. However, it can be difficult to quantify the deformational fabric of fault rocks, especially the preferred orientations of fine-grained minerals, or to uniquely determine the relationship between fabric geometry and finite strain. Here, we present the results of a fabric study of gouge and breccia sampled from low-angle normal (detachment) faults in the Black Mountains, Death Valley, CA. We measured a preferred orientation of the long axes of the clasts inherited from the crystalline footwall of the fault and compared the shape preferred orientation to the anisotropy of magnetic susceptibility of the fault rocks. The two measurements of fabric exhibit systematic similarities and differences in orientation and anisotropy that are compatible with the large-scale kinematics of fault slip. The dominant carriers of the magnetic susceptibility are micron- and sub-micron scale iron oxides and clay minerals. Therefore even the finest grains in the fault rock were sensitive to the distributed deformation and the micro-mechanics of particle interaction must have departed from those assumed by the passive-marker kinematic model that best explains the fabric. INDEX TERMS: 8010 Structural Geology: Fractures and faults; 8030 Structural Geology: Microstructures; 8025 Structural Geology: Mesoscopic fabrics; 8109 Tectonophysics: Continental tectonics—extensional (0905); 1518 Geomagnetism and Paleomagnetism: Magnetic fabrics and anisotropy

Citation: Hayman, N. W., B. A. Housen, T. T. Cladouhos, and K. Livi (2004), Magnetic and clast fabrics as measurements of grainscale processes within the Death Valley shallow crustal detachment faults, J. Geophys. Res., 109, B05409, doi:10.1029/2003JB002902.

\section{Introduction}

[2] Faulting in the top few kilometers of the crust occurs on sharp surfaces less than a millimeter wide and across wider shear zones. Shallow crustal shear zones are filled with breccia and gouge, fault rocks with clast-in-matrix textures with gouge containing respectively larger amounts of clay-sized grains [Sibson, 1977]. A noteworthy property of both gouge and breccia is the presence of fabric that is defined by the preferred orientation of grains. Fabric elements typically have a systematic angular relationship with the boundaries of the shear zone that are useful in interpreting the kinematics of fault slip [Logan et al., 1979; Rutter et al., 1986; Chester and Logan, 1987;

\footnotetext{
${ }^{1}$ Division of Earth and Ocean Science, Duke University, Durham, North Carolina, USA.

${ }^{2}$ Geology Department, Western Washington University, Bellingham, Washington, USA.

${ }^{3}$ WebPE, Inc., Edmonds, Washington, USA.

${ }^{4}$ Also at Department of Earth and Space Sciences, University of Washington, Seattle, Washington, USA.

${ }^{5}$ Department of Earth and Planetary Sciences, Johns Hopkins University, Baltimore, Maryland, USA.
}

Copyright 2004 by the American Geophysical Union. 0148-0227/04/2003JB002902\$09.00
Cowan and Brandon, 1994]. Fault rocks are also of interest in understanding the mechanics of faults because slip is partitioned between discrete planar structures and more distributed deformation [Tikoff and Teyssier, 1994]. The two different expressions of fault-related deformation may signify different rheologic responses of faults such as observed in experiments [e.g., Saffer and Marone, 2004] and nature [e.g., Linde et al., 1996]. Despite the importance of fabric in shallow crustal rocks, it is more difficult to characterize and measure these inherently discontinuous fabrics than it is to characterize fabrics in deeper crustal mylonitic rocks.

[3] In an effort to understand the development of fabric in shallow crustal shear zones we present measurements and interpretations of the shape-preferred orientation (SPO) and the anisotropy of magnetic susceptibility (AMS) from gouge and breccia sampled from detachment faults exposed in Death Valley, CA. The detachments reveal world-class exposures of centimeter-to-meter wide sections of gouge and breccia that have mesoscopic foliation [Miller, 1996; Cowan et al., 2003] and welldefined SPO [Cladouhos, 1999a]. We also present several new observations from the fault rocks including: optical, transmission, and back-scattered electron microscopy, lowtemperature magnetic experiments, partial anhysteretic 
remanent magnetization (pARM), and the anisotropy of pARM (ApARM).

[4] By comparing the SPO in three planes of view to the AMS we make some important conclusions about the manner in which fabric elements develop in shallow crustal shear zones. Notably, the SPO and AMS vectors are consistent with, and add to our understanding of, large shear strains accrued by distributed deformation across the shear zones. The data that we present collectively rule out that clasts used to measure the SPO are the primary carriers of magnetic susceptibility. Rather, the AMS is an indirect measure of the shape-preferred orientation of micron- and sub-micron scale oxides and clay minerals. However, the kinematic model that best explains the AMS and SPO data does not predict traction between rotating particles and their surrounding matrix. In a concluding discussion, we remark on the importance of the differences between theory and observation, and entertain alternative hypotheses for SPO and AMS fabrics in fault gouge and breccia.

\section{Methods}

[5] We collected over a hundred samples during the course of several field seasons and chose a subset of samples for this study. The samples were categorized into several structural map units facilitating comparison between samples based upon texture, composition, and mineralogy. To establish a reference frame for sampling, we assumed that the detachment shear zone is everywhere present and planar, and we used its dip direction as an index for the sample orientation. The samples were oriented in the field following the right hand rule with indices: $X_{1}$ parallel to the strike of the fault plane, $X_{2}$ parallel to the dip of the fault plane, and $X_{3}$ normal to the fault plane. We informally refer to the $X_{2}-X_{3}$ plane as the "dip plane", the $X_{1}-X_{3}$ plane as the "strike plane", and the $X_{1}-X_{2}$ plane as the "fault plane".

[6] All thin sections were prepared by embedding the samples in LR-White epoxy fixed for over 24 hours at $60^{\circ} \mathrm{C}$ under vacuum. The samples were polished dry with 600 Grit polishing wheels. Once polished chips were prepared no special methods were required to cut and polish the sections. Because of the extremely dry conditions in Death Valley the fault rocks are not typically water saturated in the field and remain cohesive until introduced to water.

[7] We measured SPO optically, primarily with $\sim 25 \mathrm{x}$ magnification. Thin sections were traversed with a mechanical counting stage, and the length of the longest and shortest axes of each clast was recorded. The axial ratio and orientation of any individual grain is necessarily a value of the cross-section of that grain in the plane-of-view and not the true axial ratio of the grain in three dimensions. To partly address the problem of a two-dimensional view we measured SPO vectors in three orthogonal sections for each sample. We assumed that an axial ratio (r) of greater than 1.4 was required to establish a shapepreferred orientation [Cladouhos, 1999a] and counted the orientation of more than 100 grains for most samples, a proposed cut-off for reliable SPO data [Varga, 1983]. The different clasts were grouped into three lithologic catego- ries to provide a semi-quantitative indication of the number of opaque, potentially ferrimagnetic grains in the population that defines the AMS. Attempts to automate the process of determining SPO with image processing were unsuccessful because of the low axial ratio of the clasts and the uneven contrast between clasts, matrix, and brittle microstructures.

[8] Cladouhos [1999a] presented a more systematic analysis of SPO, also summarized here, in the dip plane using $31.25 \mathrm{x}, 125 \mathrm{x}$, and $312.5 \mathrm{x}$ magnification on the optical microscope, and 48x and 200x scanning electron images (in back-scattered electron, BSE, mode) obtained on the University of Washington JEOL 733 Superprobe. Additional scanning electron microscopy was conducted at the University of Washington and on a JEOL 8600 at the Johns Hopkins University. Transmission electron microscopy (TEM), and high-resolution TEM (HR-TEM) were conducted at the Johns Hopkins University on a Philips CM300FEG 300-kV, field-emission gun electron microscope.

[9] All measurements of the magnetic properties of the fault rocks were made at the Pacific NW Paleomagnetism Lab, Western Washington University. The fault-rock samples were cut into cubes $1.5-1.8 \mathrm{~cm}$ on a side and the MS was measured using a KLY3-S Kappabridge. We related the structural reference frame of the sampling localities to the geographic reference frame of the instrument by aligning $X_{1}$, $\mathrm{X}_{2}$, and $\mathrm{X}_{3}$ to $\mathrm{N}, \mathrm{W}$, and the vertical axis, respectively. We measured the MS of 200-300 mg sub-samples of the fault rocks from $77 \mathrm{~K}$ to room temperature using a CS-3L cryostat. Partial anhysteretic remanent magnetization (pARM) was given to selected samples with a D-Tech D-2000 alternating field (a.f.) demagnetizer with a $0.5 \mathrm{mT}$ DC field produced by a built in bias coil, and measured with a 2-G model 755 Superconducting Rock Magnetometer. Each of the four samples was first a.f. demagnetized with a $200 \mathrm{mT}$ peak field. Measurements of pARM were taken using a specific window of $10 \mathrm{mT}$, between 5 to $195 \mathrm{mT}$. The specific window of measurement of the anisotropy of pARM was unique to groups of specific samples and defined by the halfheight width of the dominant peak in the pARM spectrum. An 18-orientation measurement scheme, based on the rotary design matrix of Jelinek [1978] was used, with a.f.-demagnetization performed between each step.

[10] Trends and plunges of vectors were plotted on lower hemisphere equal-angle stereonets, and rose diagrams of SPO data were plotted in $5^{\circ}$ bins, with lengths of petals drawn proportional to the percentage of the data that fall within a given bin. The strength of the SPO vector was quantitatively determined independently as described in a following section. The reference frame for each plot is such that the vertical axis plots in the center of stereonets or at the top of the rose diagrams, and the slip direction plots on the left-hand side of the net or rose diagram according to the right-and rule. Stereoplots were constructed with the program Stereoplot by R. Allmendinger. The kinematic model was developed using the Matlab scripts of Ježek and Hrouda [2002].

\section{Tectonics of the Black Mountains, Death Valley, California}

[11] The Black Mountains bound the east side of Death Valley, California, and are flanked by low and high angle 


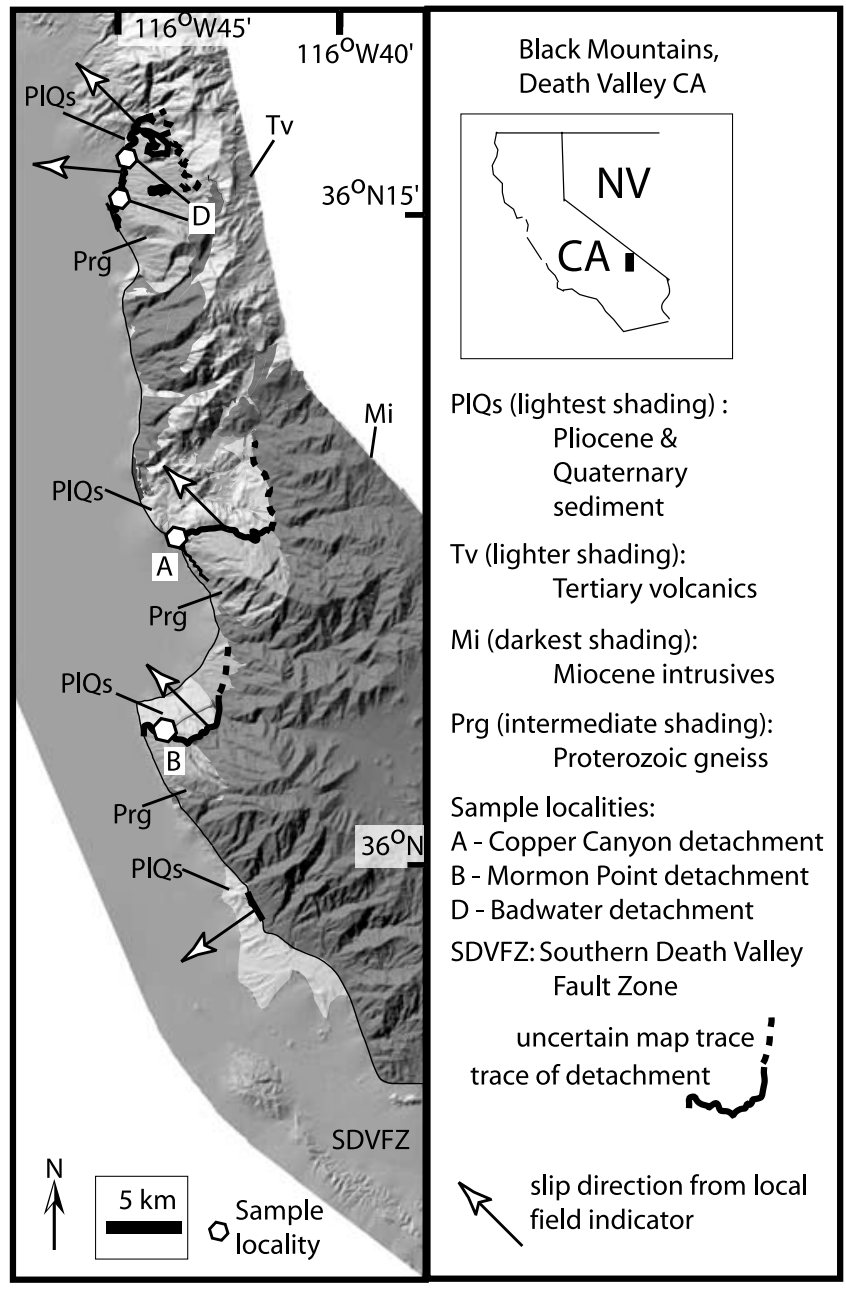

Figure 1. Compiled $30 \mathrm{~m}$ USGS DEM of the Black Mountains, Death Valley, California, just southwest of the Nevada-California border as shown on the location map in the inset to the right. Shaded map units are labeled and defined in the key to the right. Traces of detachments (bold lines) are from Drewes [1963], Miller [1996], and Wright and Troxel [1984]. Arrows are the trends of kinematic indicators such as striae on the fault planes. Samples discussed in this study were acquired from localities A, B, and D. SDFZ is the Southern Death Valley Fault Zone whose trace is unclear north of a faulted cinder cone on the valley floor (bottom-center of the DEM).

fault segments making up the Black Mountain fault system (Figure 1). The low-angle normal (detachment) faults define the upper surface of domal, "turtleback" landforms of Proterozoic metasedimentary rocks and Miocene plutons (the footwall) [Drewes, 1963; Wright and Troxel, 1984]. Recognition of several Pliocene and Quaternary tephra in the overlying sediments (the hanging wall) and the amounts of throw across subsidiary faults constrain the minimum age and amount of slip on the detachments [Holm et al., 1994; Hayman et al., 2003]. The currently exposed detachments accrued approximately $1 \mathrm{~km}$ of slip in the Quaternary, including at least a $14 \%$ stretch across the hanging wall of the detachment. Given the exposed footwall and an estimated $0.5-1 \mathrm{~mm} / \mathrm{yr}$ slip rate, there has been at least
$3.5-4 \mathrm{~km}$ of slip and associated hanging wall extension since the early Pliocene.

[12] In most places, the sense of motion across subsidiary faults, striae on slip surfaces, and kinematic indicators within the fault rock constrain the sense of slip on the detachment to be northwest-side-down dip-slip (Figures 1 and 2) [Hayman et al., 2003; Cowan et al., 2003]. Reports on this sense of motion differ and one locality exhibits evidence for oblique components of slip on the detachment [Keener et al., 1993]. Geodetic vectors between the Black and Panamint mountains are $2-4 \mathrm{~mm} / \mathrm{yr}$ to the NW and part of the displacement field attributed to transtension associated with the Eastern California Shear Zone [Miller et al., 2001]. Therefore west-dipping fault surfaces should locally accrue some oblique slip in the regional NW-directed transtension. As we demonstrate here, AMS and SPO can be used as kinematic indicators of fault slip and determine subtle variations in the local slip kinematics that accommodate the regional displacement field.

[13] Some of the slip on the Death Valley detachments accompanied prehistoric seismicity [Hayman et al., 2003]. Well-constrained main shocks on low-angle detachments world-wide are virtually non-existent [Jackson and White, 1989], and verified detachment responses to seismic slip are complicated [Axen, 1999]. Furthermore, the fault rocks we studied largely developed above the seismogenic zone. Considering the structural level of the detachment and the relationships with earthquake-scarps, we infer that some of the fabric elements in the Death Valley detachments developed during complicated responses to co- and postseismic deformation on the Death Valley detachments. Another intriguing property of the detachments is that the effective friction of the fault zone must be lower than that expected for typical earth materials [Hayman et al., 2003]. The mechanisms for multiple responses to seismicity and fault weakening may be resolved with grain-scale analyses of the fault rocks, as we describe in the concluding discussion.

\section{Fault-Rock Types, Structures, and Sample Characterization}

[14] The term fault rock is a non-genetic term for any rock that formed within a fault or shear zone. We use the term exclusive of mylonites and other rocks that contain intracrystalline strain or continuous folia such as those interpreted by most workers to have resulted from pressure solution and related creep processes [Snoke and Tullis, 1998].

[15] Fault rocks are subdivided based upon grain size and texture [Sibson, 1977; Cladouhos, 1999a; Cowan et al., 2003]. Breccia has $>20-30 \%$ visible, angular lithic clasts, foliated breccia is a breccia with a mesoscopic foliation, granular gouge has $<20-30 \%$ visible, rounded clasts, clay gouge is defined primarily by the abundance of platy aggregates of clays and clay-sized minerals, and scaly clay gouge is a clay gouge wherein the clay-sized material is arranged in distinctive, anastomosing folia. At certain localities in the Black Mountains, the different fault rocks are stratified across the detachment (Figure 2) and a $<1 \mathrm{~mm}$-wide striated slip surface separates the foliated fault rocks from the hanging wall [Cowan et al., 2003]. 

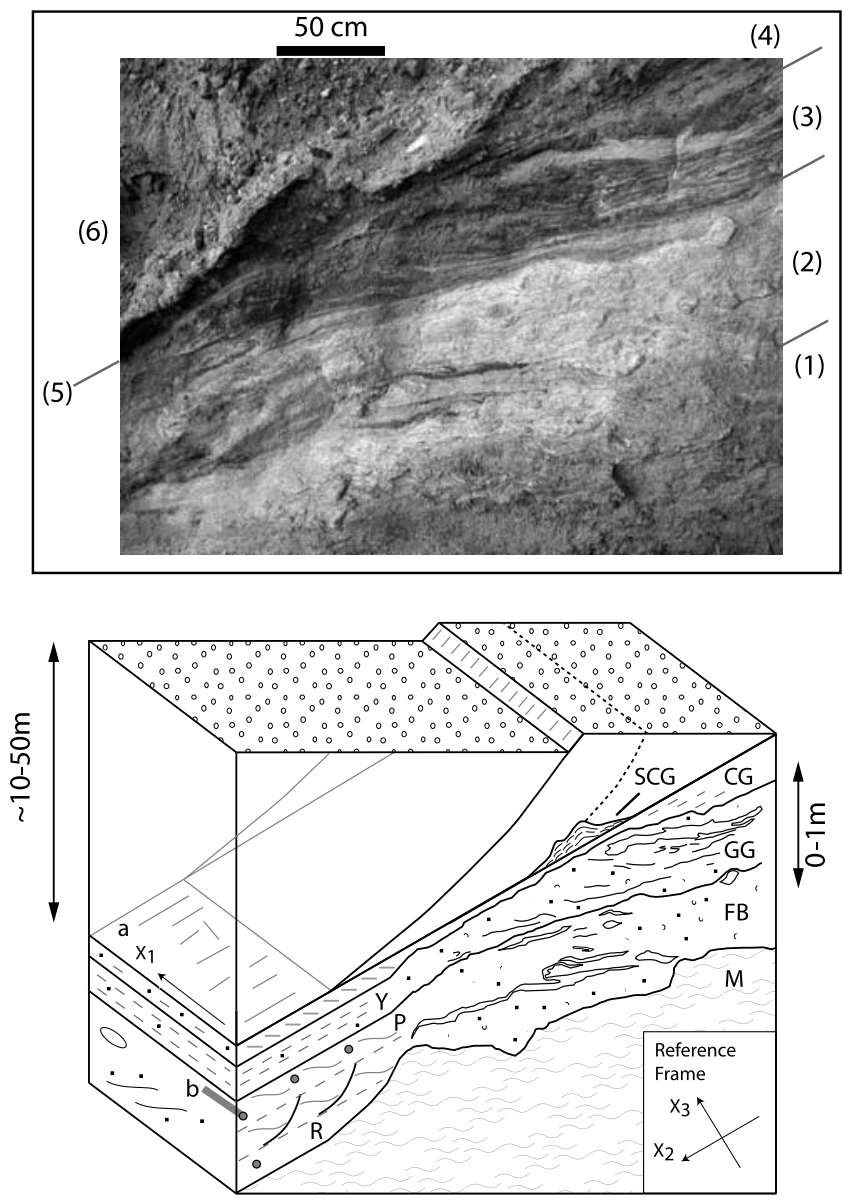

Figure 2. Death Valley detachment structure: (a) Exposure of a detachment on the Badwater turtleback. Photograph courtesy of Julia Morgan. Structural units from the bottom right to upper left of the photo are: (1) mixed quartzofeldspathic and dolomitic gneiss in the footwall, (2) foliated breccia with P-foliation and clasts from the footwall, (3) granular gouge with P-foliation and increasing amount of darker clay, (4) clay gouge (lighter gray on upper right) with a Y-foliation, (5) a sharp slip surface dipping to the west (left), and (6) hanging wall sediment of early Quaternary/late Pliocene age. (b) Schematic of the detachment system. The reference frame used in our analyses is a right-hand rule, orthogonal reference frame with $\mathrm{X}_{1}$ parallel to strike, $\mathrm{X}_{2}$ parallel to dip, and $\mathrm{X}_{3}$ normal to the fault plane; none of these axes are meant to indicate strain or stress directions. $\mathrm{SCG}=$ scaly clay gouge, $\mathrm{CG}=$ clay gouge, $\mathrm{GG}=$ granular gouge, $\mathrm{FB}=$ foliated breccia, $\mathrm{M}=$ mylonitic footwall, $a=$ lineation-orientation parallel to $\mathrm{X}_{2}, b=$ lineation-orientation parallel to $X_{1}$. Y, R, and $P$ are indices for the orientation of fabric elements as described in the text. The depiction of the fault rock on the right side of the diagram approximates the appearance of the rocks in the field, whereas the schematic to the left is more diagrammatic. Some other key elements of the detachment system depicted include: an earthquakeproduced scarp cutting Pliocene-Quaternary sediment, hanging wall faults that sole into the detachment, clay gouge protrusions into the hanging wall, and the presence of fabric elements on the $\mathrm{X}_{1}-\mathrm{X}_{3}$ plane.
Slip surfaces contain ultracataclasite, differentiable from gouge and breccia by having $>90 \%$ finely comminuted material [Sibson, 1977].

[16] The term cataclasite encompasses all of the fault rocks that we describe here. However, cataclasite has a genetic connotation that the rocks deformed via cataclastic flow, a specific deformation mechanism wherein strain is accommodated by the combined effects of slip on multiple surfaces and/or fracture accompanying the rolling and sliding of grains past one another [see Twiss and Moores, 1992, pg. 388]. Whereas breccias are cataclasites (Figure 3a), gouges do not exhibit syn-tectonic, transgranular fracture in thin sections (Figure $3 b$ ). In contrast with the cataclastic flow that is inferred to have produced breccias, gouges are inferred to be the product of granular flow [see Twiss and Moores, 1992, pg. 388] wherein particles interact inelastically due to the friction of grain contacts but do not fail internally [Morgan, 1999; Morgan and Boettcher, 1999].

[17] Within the gouge and breccia are systematically oriented slip surfaces and foliation that are provided indices to help in their analysis (Figure 2) [Cladouhos, 1999a; Cowan et al., 2003]. R refers to synthetic (down-dip facing) riedel structures, $\mathrm{P}$ refers to structures inclined to the fault plane, and Y refers to structures parallel to the fault plane. The indicical terminology shares similarities with the S-C terminology for mylonitic rocks [e.g., Lister and Snoke, 1984] although its usage is tailored specifically for shear bands in experiments investigating the brittle field [Logan et al., 1979]. These structural indices consistently describe fabric elements in natural shear zones [Chester and Logan, 1987; Cowan and Brandon, 1994].

[18] The samples that we chose for this study come from specific exposures of the Copper Canyon (A-series), Mormon Point (B-series), and Badwater (D-series) detachments (see Methods section). The fault-rock samples include foliated breccia (A3, B34, D3), granular gouge (A6, A13, B2, D2), clay gouge (A1, B1, D4, D11), scaly clay gouge (A11), and ultracataclasite (D14) (Table 1). The samples are representative of each structural unit at each locality.

[19] The fault-rock samples have been characterized by extensive compositional and textural analysis [Hayman, 2003] summarized here with emphasis on aspects that relate to the proper interpretation of the SPO and AMS. For the purposes of discussion we approximate the texture of the gouge and breccia as a "clast-in-matrix" texture (Figure 3). We note that the approximation of two populations of grains is only for convenience. The fault rocks have a power law grain size distribution [Morgan et al., 1996] so that most size fractions will have a self-similar clast-in-matrix texture.

[20] Clasts are grains used to measure the SPO in thin section with diameters typically larger than $50 \mu \mathrm{m}$. Grain counts from six samples (Figure 4) show that the clasts are dominantly of the same lithology as the footwall: quartzofeldspathic or micaceous schists and gneisses or less common dolomitic gneiss. In some sections as many as $10 \%$ of the clasts are derived from the hanging wall including cemented sediment, angular fragments of nonmylonitic crystalline rocks, and rare volcanics. The larger clasts are deficient in mafic and opaque minerals with less 

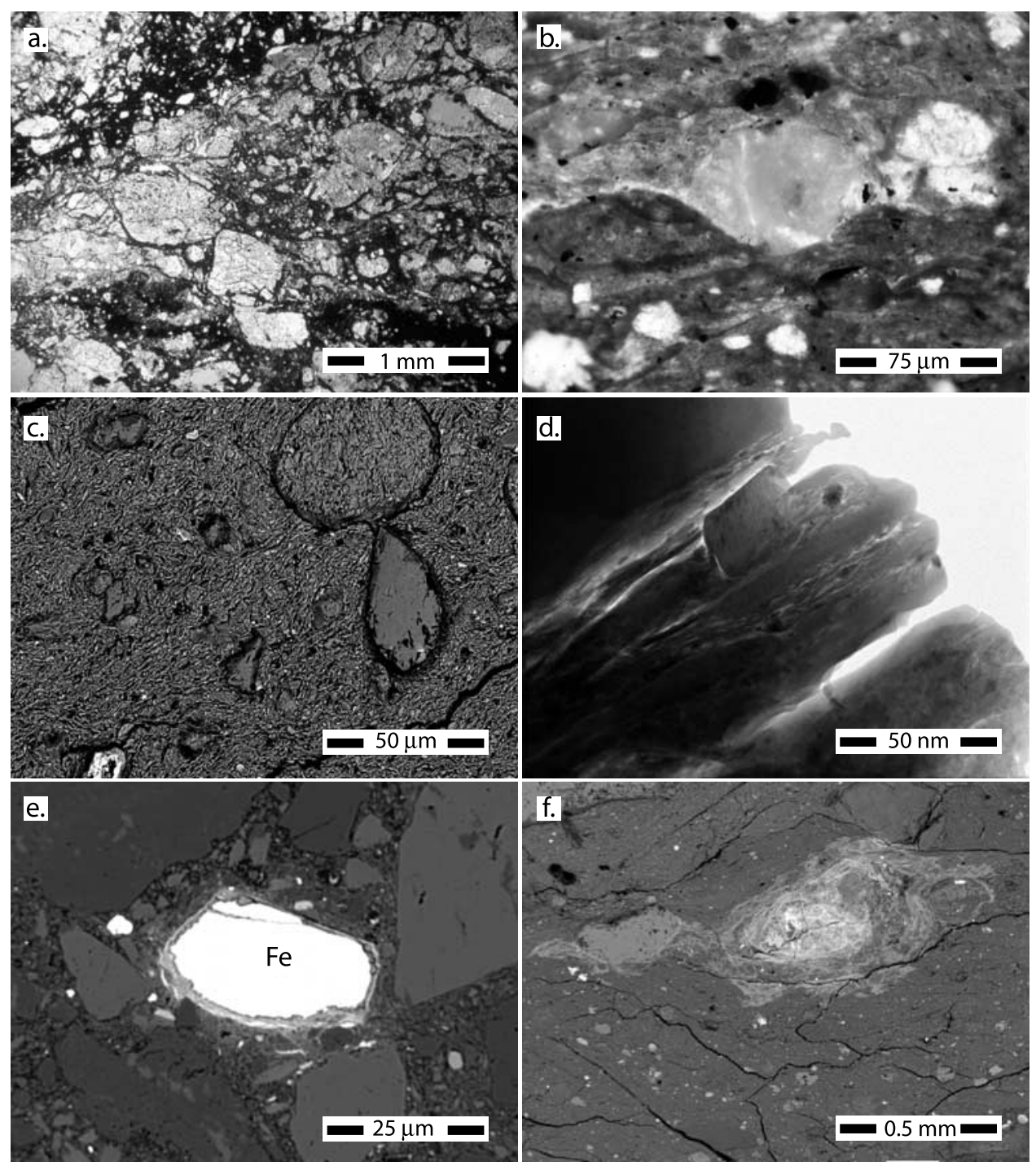

Figure 3. Microstructure of gouge and breccia: (a) Photomicrograph (in plane-polarized light) of a foliated breccia from Mormon Point. Note the weak fabric and the trans-granular fractures and grain-ongrain contacts with interstitial clay-sized minerals. (b) Clay gouge from Copper Canyon turtleback. Note that any trans-granular fractures are relicts, there are few grain-on-grain contacts, and the abundant, foliated, clay-sized matrix. Careful inspection of the photomicrograph reveals fine opaques within the matrix. (c) Back-scattered electron image (BSEI) of Badwater clay gouge D4. The large (ca $50 \mu \mathrm{m}$ ) clasts are dolomite, quartz, and lithic fragments inherited from the footwall. We interpret the rounded clast on the top-center-right of the image to be a cemented and remobilized clast of the matrix material. The surrounding matrix is an aggregate of clay-sized minerals, the majority of which are phyllosilicates, some of which grew within the fault zone and were subsequently rotated by distributed deformation. (d) TEM image of a grain within the fine-grained matrix of clay gouge D4. The lath in the center of the image is interstratified illite/smectite with a rhomb-shaped inclusion of (late) dolomite. Adjacent to the dolomite is a small inclusion of a Fe-bearing phase that we discuss in the text and interpret to be ultra-fine magnetite. (e) $25 \mu \mathrm{m}$ grain of an iron oxide in BSEI of sample D11. Note the ultra-fine oxide particles that create a "halo" around the grain indicating post-tectonic precipitation of oxides. (f) BSEI of sample A26, a scalyclay gouge that is similar to sample A11. The grain in the center of the image is a rhodochrosite-rich fragment that is surrounded by Mn-rich particles. There has been some late distributed deformation creating the anisotropic distribution of oxides that resembles a down-dip sense-of-shear indicator.

than $5 \%$ of the observed clasts having opaque grains as major constituents. Importantly, the fabric within the grain boundaries of clasts inherited from schists or mylonites does not appear to be parallel to the foliation defined by the arrangement of particles (the shape-preferred orientation).
[21] The matrix of the fault rock is a catchall term for the particles that surround the larger ca.50 $\mu \mathrm{m}$ clasts (Figures $3 \mathrm{~b}$ and $3 \mathrm{c}$ ). X-ray diffraction and X-ray fluorescence analyses of the fault rocks presented elsewhere [Hayman, 2003] demonstrate that the $<2 \mu \mathrm{m}$ size fraction 
Table 1. Sample Descriptions and Results of Cladouhos [1999a]

\begin{tabular}{lcccc}
\hline Sample & Type & $\mathrm{v}^{\mathrm{a}}$ & $\mathrm{a}$ & $\mathrm{R}$ \\
\hline A1 & Clay Gouge & 156 & 0.34 & 1.96 \\
A3 & Foliated Breccia & 144 & 0.59 & 2.17 \\
A6 & Granular Gouge & 178 & 0.46 & 1.9 \\
A11 & Scaly Clay Gouge & 159 & 0.65 & 1.98 \\
A13 & Clay Gouge & 164 & 0.56 & 2.05 \\
B1 & Granular Gouge & 9 & 0.59 & 1.89 \\
B2 & Granular Gouge & 10 & 0.38 & 1.97 \\
B34 & Foliated Breccia & & & \\
D2 & Granular Gouge & 176 & 0.71 & 1.78 \\
D3 & Foliated Breccia & 165 (BSEI) & 0.36 & 1.71 \\
D4 & Clay gouge & & & \\
D11 & Clay Gouge & 163 & 0.59 & 1.81 \\
D14 & Slip Surface & 170 (BSEI) & 0.5 & 1.8 \\
\hline
\end{tabular}

${ }^{\mathrm{a}} \mathrm{v}$ is the orientation of the SPO vector in degrees clockwise from the Y-orientation, a is the vector strength, and $\mathrm{R}$ is the average axial ratio of the clasts.

is dominated by clay minerals. The clay mineral phases are illite (in B-series samples from the Mormon Point detachment), interstratified illite-smectite (in D-series samples from the Badwater detachment), and interstratified chlorite-saponite (in A-series samples from the Copper Canyon detachment). Some of these phases, and smectitic phases in particular, must have grown within the detachments during the overall geologic interval of fault slip [Vrolijk et al., 1997; Vrolijk and Van der Pluijm, 1999; Hayman, 2000].

[22] In some samples the detailed mineralogy of the clay size fraction is more complicated. For example, transmission electron microscopy (TEM) of representative gouge sample D4 (Badwater detachment) demonstrates the presence of ultra-fine particles of non-phyllosilicate minerals within a micron-scale field of view (Figure 3d). Most noteworthy in the TEM image is a $30 \mathrm{~nm}$-diameter grain that we interpret to be nanoscale magnetite based upon Fe-peaks in energy dispersive Xray spectroscopy (EDS), lattice fringes spaced 2.8A apart in a patchwork manner, and selected area electron diffraction patterns [Hayman, 2003]. Reconnaissance EDS analyses of micron-scale aggregates also shows a stoichiometrically disproportionate amounts of $\mathrm{Fe}$ in otherwise phyllosilicate-rich material. The capacity of magnetite grains to adhere to, and mix with foliation-defining phyllosilicates and clays is known [Kodama and Sun, 1990], and magnetite and similar oxides are a natural bi-product of authigenic processes. An important and open alternative hypothesis is that the iron oxides may be maghemite (oxidized magnetite) or hematite.

[23] The size-fraction between 2 and $50 \mu \mathrm{m}$ grains does not appear to contain abundant authigenic minerals and the modal mineralogy of the silt size fraction is likely similar to the larger clast population. Two noteworthy observations of the $2-50 \mu \mathrm{m}$ size-fraction are the abundance of oxides (including iron oxides) and that some of these minerals developed during late-stage alteration of the fault rock. The later alteration is best observed in the distribution of the elemental abundance of iron and manganese in backscattered electron microscopy (BSE) (Figures 3e and 3f). Importantly, in some samples the latest phase of alteration (precipitation of manganese oxides nearby "parent" grains of rhodochrosite and other manganese- based minerals) pre-dates the most recent distributed deformation (Figure 3f).

\section{Shape-Preferred Orientation (SPO)}

[24] Shape-preferred orientation is a statistical measure of the orientation of the long axes of a population of prolate or oblate grains [Rutter et al., 1986; Chester and Logan, 1987]. There are several limitations in using SPO to study gouges and breccias. In practice, SPO is a laborintensive measurement of the axial ratios and orientations of thin-section scale clasts that are entrained in a finer grained matrix. Because of heterogeneity at higher magnification, partly imposed by the narrower field of view, SPO does not efficiently measure the fabric in the finer, micronand sub-micron scale matrix [Cladouhos, 1999a]. Furthermore, measurements of SPO are on two-dimensional thin sections and therefore any individual measurement of axial ratio and orientation is apparent and not a principal vector of a three dimensional fabric. Lastly, interpretations of SPO are inherently non-unique. The inclination of the principal vector of the SPO relative to the shear zone boundary is either interpreted as being directly proportional to the shear strain [March, 1932; Chester and Logan, 1987], or else as defining a line of net zero rotation within a flow field [Ghosh and Ramberg, 1976; Cladouhos, 1999b]. Nonetheless, SPO is one of the few methods at our disposal to quantify fabric at the grain scale and we present methods to deal with some of the difficulties inherent in the technique, including (in following sections) the measurement of AMS.

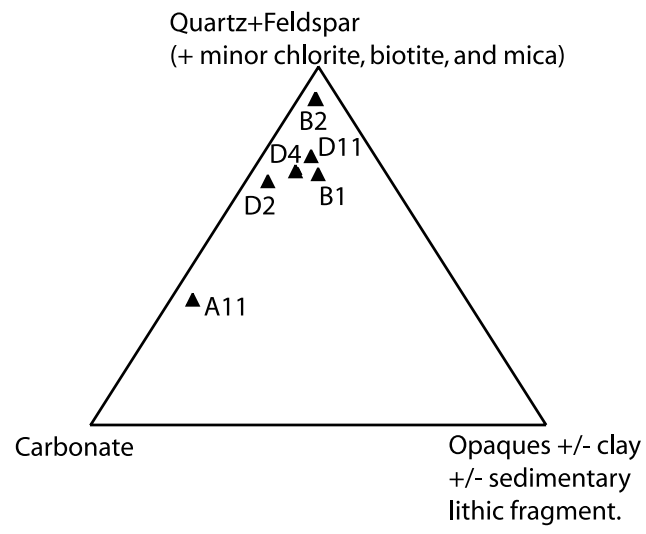

Figure 4. A ternary diagram for clast-composition in the fault rocks: apices are: $100 \%$ clasts of dominantly quartz and feldspar mineralogy (including mica- and chlorite- rich schists), $100 \%$ carbonate clasts, and $100 \%$ mixed lithologies including rock-fragments of sedimentary conglomerates, aggregates of clay, and oxides. We interpret these results to mean that $<15 \%$ of the clast population of any sample is derived from the hanging wall, and that $<5 \%$ of the clast population contributed strongly to ferrimagnetism of fault rocks. We also note that the internal fabric of any clast is not parallel to the foliation in the fault rocks. The number of clasts identified for each sample is roughly equal to the number measured for the study of SPO, several hundred grains for each sample. 

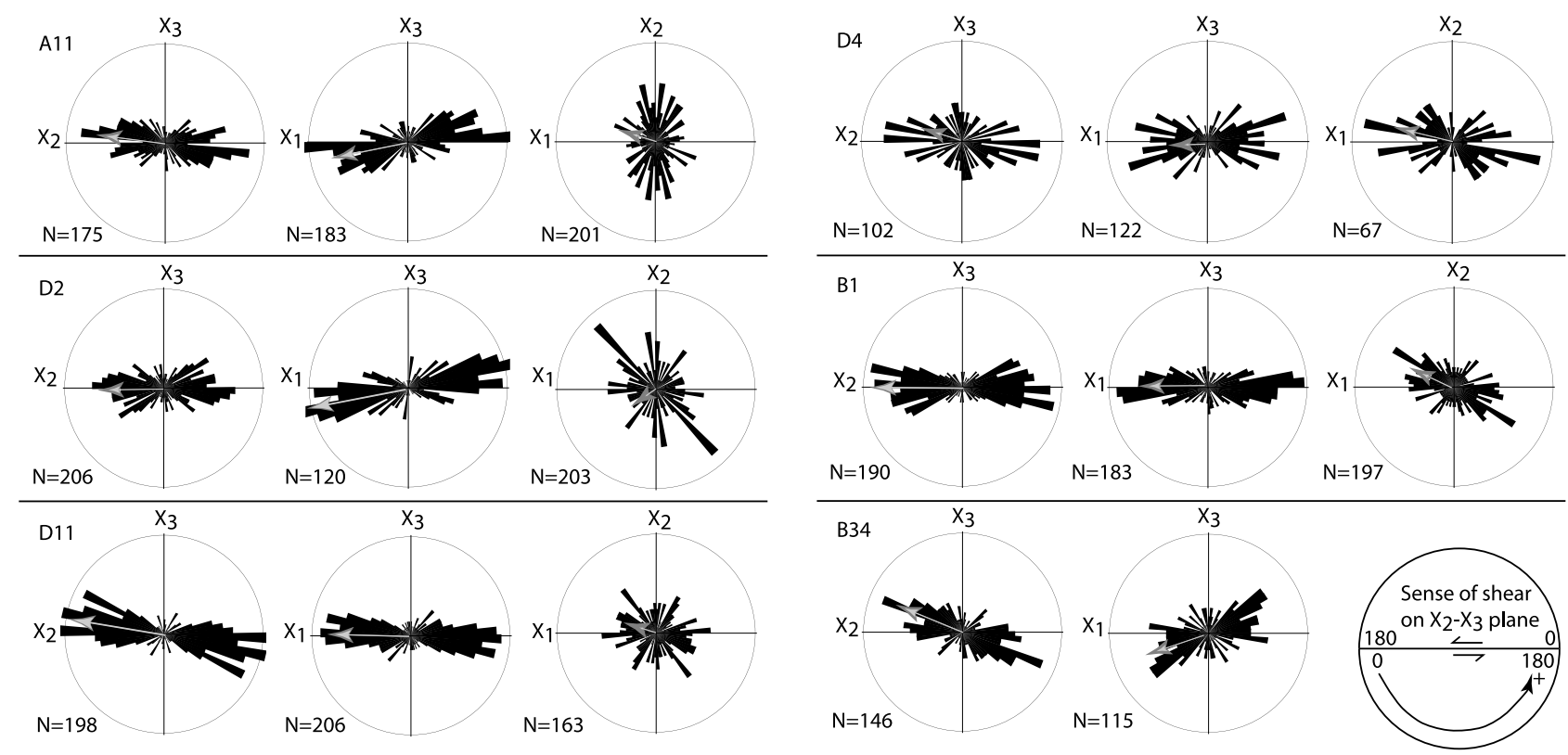

Figure 5. Rose diagrams of the shape preferred orientation measured from thin sections cut from three orthogonal planes through the samples. The data are plotted in $5^{\circ}$ bins, with lengths of petals drawn proportional to the percentage of the data that fall within a given bin. Independently determined vectors (shaded) are normalized such that the maximum vector strength is one unit-length, and others are the appropriate percentage length. Measurements of angles are counter-clockwise from the horizontal. For example, $90^{\circ}<\mathrm{SPO}$-vector $<180^{\circ}$ is a P-foliation, $0^{\circ}<\mathrm{SPO}$-vector $<90^{\circ}$ is an R-foliation, and SPOvector $\cong 0^{\circ}$ is a Y-foliation, each indicating a left-lateral sense-of-shear with respect to the horizontal of the rose diagram. $\mathrm{N}$ is the number of grains measured. $\mathrm{N}>100$ for all but one thin section, $\mathrm{D} 4$, that has a well-defined SPO with 67 measured grains. Inclined SPO-vectors in $\mathrm{X}_{1}-\mathrm{X}_{3}$ and weak SPO in $\mathrm{X}_{1}-\mathrm{X}_{2}$ indicate an out-of-plane component to the strain of the fault rock.

[25] By measuring SPO on three different planes of view we hoped to characterize the SPO given the impact of a two-dimensional view of any given thin section. Rose diagrams (Figure 5) give a qualitative visualization of the SPO. A more quantitative measure of SPO is given by the semicircular mean vector $(\bar{v})[$ Agterberg, 1974]:

$$
\bar{v}=\frac{1}{2} \times \tan ^{-1}\left(\frac{\sum \sin 2 \theta_{i}}{\sum \cos 2 \theta_{i}}\right)
$$

and the vector strength $(|a|)$ :

$$
|a|=\frac{1}{N}\left\{\left(\sum \sin 2 \theta_{i}\right)^{2}+\left(\sum \cos 2 \theta_{i}\right)^{2}\right\}^{\frac{1}{2}}
$$

for the population $(N)$ of measurements of orientation $\left(\theta_{i}\right)$ (Tables 1 and 2). The measure of $\bar{v}$ and $|a|$ is presented as a grey vector superposed on the rose diagrams on
Figure 5 . We restricted our analyses to $\sim 25 \mathrm{X}$ magnification given the analysis of Cladouhos [1999a] revealing that the orientation of the SPO vector $(\bar{v})$ remains roughly constant at all magnifications, although the vector strength $(|a|)$ is lower for SPO determined from higher magnifications.

[26] The SPO vector is well defined in the dip plane of all samples, and is consistent with normal-sense slip on the detachments according to the standard interpretation of $\mathrm{P}$, $\mathrm{Y}$, and $\mathrm{R}$ fabric elements. Interestingly, samples contrast in the dominance of any particular fabric element with granular gouge samples (D2, B1) having a dominant Yfabric, clay gouge and foliated breccia samples (A11, D11, D4, B34) exhibiting a strong P-fabric, and the dispersion of data around the fault plane defining composites of $\mathrm{P}, \mathrm{Y}$, and R fabrics for certain samples. For example, sample B1 has a strong grouping of grain axes roughly $10^{\circ}$ counterclockwise from the fault plane in addition to the horizontal SPO vector producing a composite P-Y fabric.

Table 2. Shape-Preferred Orientation (SPO) Data From This Study

\begin{tabular}{lccccccccc}
\hline Sample & V: X2-X3 & a: X2-X3 & R: X2-X3 & V: X1-X3 & a: X1-X3 & R: X1-X3 & V:X1-X2 & a: X1-X2 & R: X1-X2 \\
\hline A11 & 172.55 & 0.4 & 1.89 & 11.43 & 0.46 & 2.16 & 162.86 & 0.17 & 2.09 \\
B1 & 179.57 & 0.59 & 1.96 & 0.48 & 0.38 & 2.07 & 154.7 & 0.22 & 2.01 \\
B34 & 157.64 & 0.43 & 1.98 & 18.66 & 0.34 & 1.93 & & & \\
D2 & 1.03 & 0.37 & 2.01 & 10.93 & 0.65 & 1.98 & 125.35 & 0.09 & 1.95 \\
D4 & 162.86 & 0.18 & 1.89 & 1.79 & 0.14 & 2.04 & 166.34 & 0.33 & 1.89 \\
D11 & 170.53 & 0.63 & 2.06 & 178.52 & 0.5 & 1.95 & 162.67 & 0.12 & 1.96 \\
\hline
\end{tabular}


[27] The strike plane also contains well defined SPO with the SPO vector either inclined a few degrees clockwise from the fault plane (samples A11, D2, B34) or parallel to the fault plane (samples D11, D4, B1), and the distribution of data around the fault plane define composite fabrics. Orientation of the SPO vector is not dependent upon lithology as observed in the dip plane. Equally interesting is the presence of weakly defined SPO in the fault plane. For example, sample A11 has a poorly defined SPO vector, but the clustering of petals in the rose diagram is suggestive of an SPO vector that plunges in the dip direction. Several other samples have weak to moderately defined SPO vectors that are oriented roughly $45^{\circ}$ to the strike and dip of the fault plane.

[28] The analysis of SPO presented here confirms the initial findings of Cladouhos [1999a] that SPO vectors exist within the Death Valley fault rock that are consistent with $\mathrm{P}-, \mathrm{Y}-$, and R- fabric development in a regime of particle reorientation within a normal-sense shear zone. However, efforts to date have treated the detachments as an overall plane-strain environment [Cladouhos, 1999a, 1999b; Cowan et al., 2003]. The measurements of well-defined SPO in the strike plane, and correspondingly less welldefined SPO in the fault plane, are evidence that there is an out-of-plane component to the strain as manifest in particle reorientation. The weak SPO within the fault plane is evidence for a pitch to the north in the flow field, consistent with the regional NW tectonic extension. If, as we propose, a northward component of fault slip is the reason for the out-of-plane SPO, then the SPO vectors in the strike planes are in a R-, Y-, and composite R-Y orientation. The grounding of the SPO measurements in the established kinematics of fault slip also allows us to proceed with the description of AMS in the proper tectonic context.

\section{Anisotropy of Magnetic Susceptibility}

[29] Magnetic susceptibility (MS) is a third-rank tensor, $k_{i j}$, that relates the natural magnetization, $M_{i}$, to an applied magnetic field, $H_{j}$ :

$$
M_{i}=k_{i j} \bullet H_{j}
$$

The principal directions (eigenvectors) of the $k_{i j}$ have values $k_{1}, k_{2}$, and $k_{3}$; in practice the principal vectors are normalized to a unit-length. For SI volume-normalized magnetic units, MS is dimensionless. The mean susceptibility $k_{\text {mean }}$ is defined by:

$$
k_{\text {mean }}=\frac{k_{1}+k_{2}+k_{3}}{3}
$$

[30] In samples that have $k_{1}>k_{3}$, the MS has an anisotropy quantified by relations [Hrouda, 1982]:

(a) $P=\frac{k_{1}}{k_{3}}$; (b) $L=\frac{k_{1}}{k_{2}}$; (c) $F=\frac{k_{2}}{k_{3}}$; (d) $T=2 \times\left[\frac{\log \left(\frac{k_{2}}{k_{3}}\right)}{\log \left(\frac{k_{1}}{k_{3}}\right)}\right]-1$

[31] The AMS ellipsoid corresponds closely to that of the finite strain ellipsoid in many instances [Borradaile, 1991] and provides a valuable tool for developing kinematic models of fabric development [Tarling and Hrouda, 1993; Ježek and Hrouda, 2002]. Although a bulk-rock property, the AMS ellipsoid effectively defines an SPO for magnetite, or a lattice preferred orientation (LPO) for most other minerals [Nye, 1985; Richter, 1991]. While AMS is considered a more approximate indicator of fabric orientation and intensity than SPO, it is relatively labor-free, and can provide information on a larger spectrum of grain-sizes with one measurement.

[32] The AMS of the fault rocks is typified by moderately to shallowly plunging maximum principal vectors $\left(k_{1}\right)$ and steeply plunging minimum principal vectors $\left(k_{3}\right)$. The orientation of $k_{1}$ for the sample population is not restricted to the dip plane, but rather the vectors plunge in many orientations, as best viewed on a stereonet (Figure 6a). The orientation of $k_{3}$ for the sample population is less scattered than that of $k_{1}$, although there are also outliers in the orientations of $k_{3}$ (Figure 6b).

[33] Similar to strain markers AMS data can be separated into prolate ellipsoids with $T<0$ (Table 3 ) and plot above a line with a slope of unity on a Flinn-type plot (Figure 6c). Oblate AMS ellipsoids have $T>0$ and plot below the line $L / F=1$. The fault rocks from Death Valley typically have low anisotropy $(\mathrm{P}<1.04)$, with the samples of ultracataclasite, clay, and scaly clay gouge having a higher anisotropy than the samples of granular gouge and foliated breccia.

[34] Three samples (A13, A6, and D4) have prolate AMS ellipsoids and these three samples coincidentally have $k_{1}$ vectors that are close to lying within the $X_{1}-X_{3}$ (strike) plane. Interestingly, one of the prolate AMS ellipsoids from sample A6 has a shallowly plunging $k_{3}$ minimum vector, a phenomena that may be associated with inverse AMS fabrics wherein the minimum and maximum vectors of the AMS ellipsoid are inverted. In metamorphic tectonites linear fabric elements that are roughly orthogonal to the dip of the fault are termed $b$ lineations, whereas linear fabric elements that plunge in the dip direction are termed $a$ lineations [Sander, 1930]. AMS fabrics that define a lineation in $b$ have been identified as the intersection of two foliations [Housen et al., 1993] such as composite P-Y foliation. Similarly, inverse fabrics have been attributed to a number of mechanisms involving grain reorientation [Richter, 1991; Rochette et al., 1999]. We explore a kinematic explanation for these anomalous AMS fabrics in a following section. First, we systematically compare the SPO and AMS of certain samples to better understand how the two fabrics relate to one another.

\section{Comparison of SPO and Anisotropy of Magnetic Susceptibility (AMS)}

[35] Both AMS and SPO provide meaningful information about the fabric orientation in the Death Valley fault rocks. SPO vectors directly relate to kinematically significant fabric orientations. The minimum principal vectors of the AMS fabrics track poles to the foliations, and the maximum principal vectors are shallowly plunging, albeit scattered in their trends, consistent with the overall fabric orientation such as measured with SPO. We now systematically compare the AMS and SPO in several individual samples (Figure 7) in order to: evaluate the significance of the scatter of $k_{1}$ in the sample population, to help understand the physical significance of the AMS and SPO, and to find 


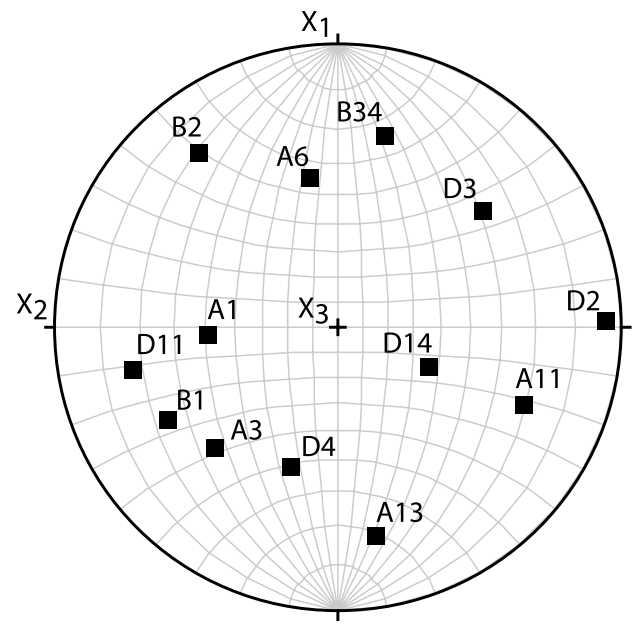

$\mathrm{k}_{1}$ - Maximum axis of the AMS ellipsoid

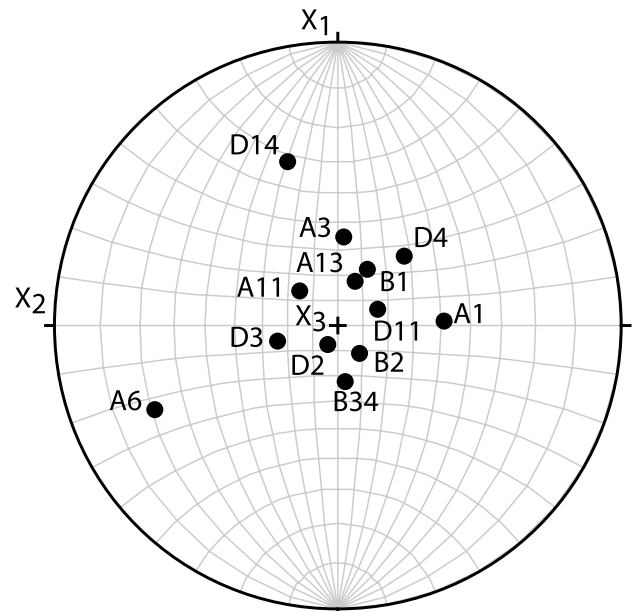

k3 - Minimum axis of the AMS ellipsoid

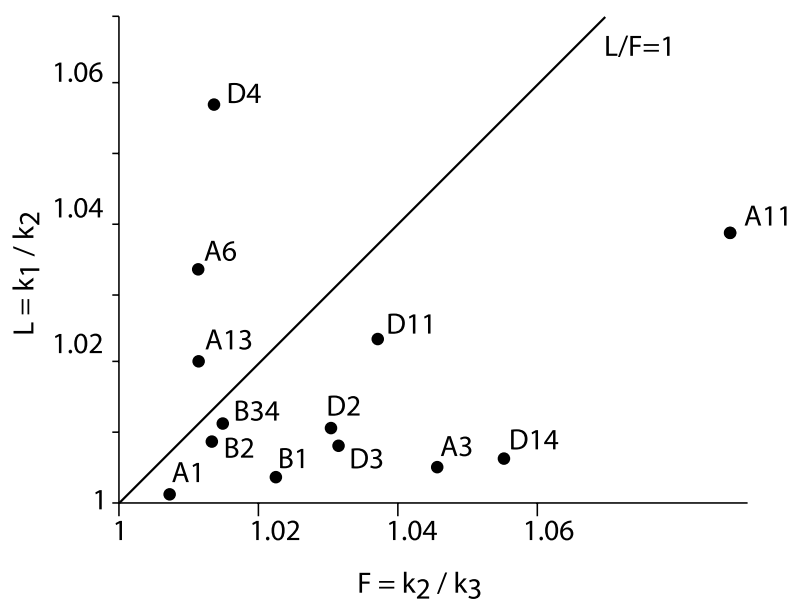

Figure 6. AMS data (a) plotted on lower-hemisphere, equal-angle nets. (left) The long-axes of the maximum principal vector of the AMS ellipsoids for all samples with respect $+\mathrm{X}_{2}$ on the left, $+\mathrm{X}_{1}$ on the top - each horizontal unit vector plots on the primitive of the net. $+\mathrm{X}_{3}$, the vertical unit vector, plots in the center. (right) Stereprojection of the minimum axes of the AMS ellipsoids for all samples. For most samples, $\mathrm{k}_{1}$ (maximum principal vector) plots at a low angle to the shear plane (the primitive), and $\mathrm{k}_{3}$ plots at a high angle to the shear plane. (b) Flinn-type diagram of measures of anisotropy of magnetic susceptibility, L and F. Samples A13, A6, and D4 have prolate AMS ellipsoids, whereas the other samples have more oblate AMS ellipsoids. Interestingly, samples A6, D4, and A13 have maximum principal vectors that lie near or within the $X_{1}-X_{3}$ plane (a b-lineation), and $A 6$ has an inverse fabric wherein the minimum principal vector is at a high angle to $\mathrm{X}_{3}$.

Table 3. Anisotropy of Magnetic Susceptibility (AMS) ${ }^{\mathrm{a}}$

\begin{tabular}{lccccccccccccccccc}
\hline Sample & $k_{1}$ & Dec- $k_{1}$ & Inc- $k_{1}$ & $k_{2}$ & Dec- $k_{2}$ & Inc- $k_{2}$ & $k_{3}$ & Dec- $k_{3}$ & Inc- $k_{3}$ & kmean & P \\
\hline A1 & 1.0034 & 267 & 41 & 1.002 & 177 & 0 & 0.9946 & 87 & 49 & $1.21 \mathrm{E}-01$ & 1.0088 & 1.0014 & 1.0074 & 0.683 \\
A3 & 1.0181 & 225 & 27 & 1.013 & 125 & 20 & 0.9689 & 4 & 56 & $1.03 \mathrm{E}-03$ & 1.0508 & 1.005 & 1.0455 & 0.7959 \\
A6 & 1.0261 & 349 & 34 & 0.9925 & 131 & 50 & 0.9813 & 245 & 19 & $1.03 \mathrm{E}-03$ & 1.0457 & 1.0339 & 1.0114 & -0.4927 \\
A11 & 1.0513 & 113 & 19 & 1.012 & 205 & 6 & 0.9307 & 313 & 70 & $1.02 \mathrm{E}-03$ & 1.1296 & 1.0388 & 1.0874 & 0.3751 \\
A13 & 1.0171 & 169 & 16 & 0.997 & 262 & 10 & 0.9858 & 22 & 71 & $1.90 \mathrm{E}-03$ & 1.0318 & 1.0202 & 1.0114 & -0.2758 \\
B1 & 1.0098 & 241 & 21 & 1.0062 & 146 & 12 & 0.984 & 28 & 65 & $7.37 \mathrm{E}-05$ & 1.0262 & 1.0036 & 1.0226 & 0.7282 \\
B2 & 1.0126 & 321 & 14 & 1.0011 & 231 & 0 & 0.9863 & 141 & 76 & $1.49 \mathrm{E}-04$ & 1.0267 & 1.0115 & 1.015 & 0.1301 \\
B34 & 1.0102 & 13 & 21 & 1.0015 & 280 & 1 & 0.9883 & 173 & 68 & $9.54 \mathrm{E}-05$ & 1.0222 & 1.0087 & 1.0134 & 0.2125 \\
D2 & 1.017 & 89 & 3 & 1.0063 & 358 & 7 & 0.9766 & 202 & 82 & $5.91 \mathrm{E}-05$ & 1.0414 & 1.0106 & 1.0304 & 0.4765 \\
D3 & 1.0157 & 51 & 23 & 1.0076 & 145 & 9 & 0.9768 & 255 & 65 & $4.91 \mathrm{E}-05$ & 1.0398 & 1.008 & 1.0315 & 0.5893 \\
D4 & 1.042 & 199 & 35 & 0.9856 & 298 & 12 & 0.9725 & 44 & 53 & $7.11 \mathrm{E}-04$ & 1.0715 & 1.0572 & 1.0135 & -0.6116 \\
D11 & 1.0278 & 258 & 17 & 1.004 & 167 & 2 & 0.9681 & 69 & 72 & $1.19 \mathrm{E}-03$ & 1.0617 & 1.0237 & 1.0371 & 0.2169 \\
D14 & 1.0219 & 114 & 51 & 1.0155 & 239 & 25 & 0.9626 & 343 & 28 & $1.61 \mathrm{E}-04$ & 1.0616 & 1.0063 & 1.055 & 0.7913 \\
\hline
\end{tabular}

${ }^{\mathrm{a}}$ Dec, declination; Inc, inclination; $\mathrm{kx}$, eigenvalue. 

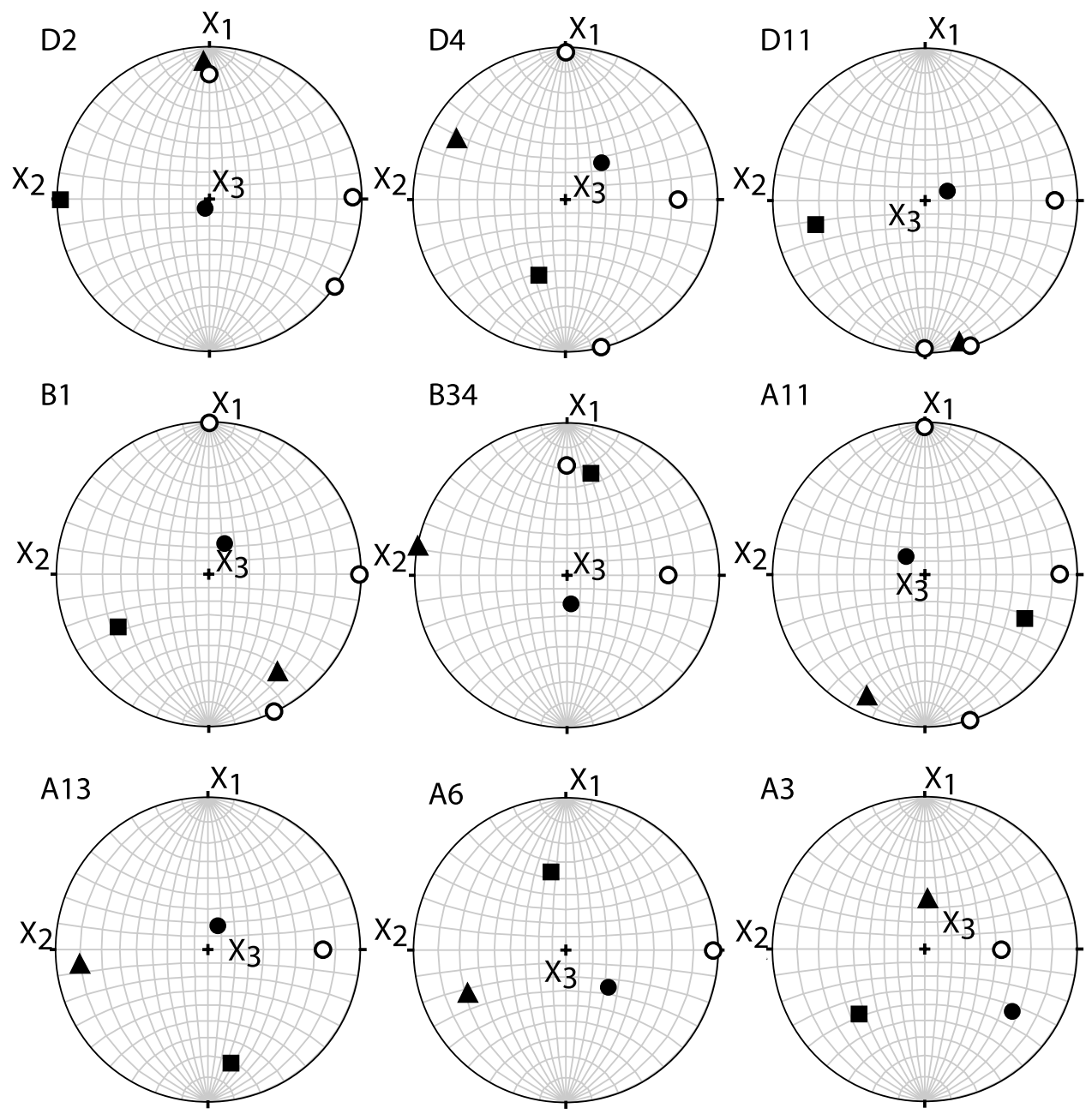

Figure 7. Stereoplots of AMS and SPO data for individual samples. Reference frame and net are the same as that for Figure 6. Note that squares are the maximum, circles are the minimum, and triangles are the intermediate principal vectors of the AMS ellipsoid. Open circles are the SPO-vectors for each plane. Samples B34, A6, and A3 do not have SPO data for all three planes. We interpret similarities between the SPO and AMS are found for samples D2, D11, B1, B34, and A13, although only sample D2 has truly coaxial AMS and SPO vectors. A13 has a well-developed $b$-lineation wherein the maximum principal vector of the AMS-ellipsoid lies within the X1-X3 plane. A6 and A3 exhibit AMS maximum and intermediate vectors that are inverted from one another.

information to relate these measures of fabric elements to the kinematic evolution of the fault-rock fabric.

[36] Any comparison of AMS and SPO needs to take into account several known aspects of the two measurements of fabrics. Firstly, the SPO does not necessarily measure principal vectors of the flow field except in cases when the rotation of grains is restricted to one plane, such as the $\mathrm{X}_{2}-\mathrm{X}_{3}$ dip plane. Secondly, the AMS is dependent on the mineralogical carriers of susceptibility and their distribution, shape, and orientation-distribution. Therefore the vectors of AMS and SPO should only be parallel in the case where AMS is produced by the shape preferred orientation of the same grains that define the SPO, or the case when all of the particles in the rock respond to fabric forming processes in the same way.

[37] The petrographic inspection of the fault rocks presented in a previous section, and an exploration of the magnetic carriers in the following section each suggest that the AMS and SPO are produced by different populations of grains. Therefore it is especially intriguing that there are some systematic similarities between the SPO and AMS (Figure 7). For example, sample D2 has two SPO vectors that are within $4^{\circ}$ of the equivalent AMS vectors. Several other samples such as samples A11, D11, and B1 also have compatible SPO and AMS vectors with the divergence between the two fabrics being within $\pm 16^{\circ}$.

[38] There are three samples D4, B34, and A13 with the maximum principal vectors of the AMS oriented within $\pm 10^{\circ}$ of being normal to the SPO vector in the dip plane. All three of the samples are either prolate (D4) or have L very nearly equal to $F$ (B34 and A13) (Figure 6c) suggesting that these AMS fabrics fall into the category of a lineation in $b$ or being parallel to the intersection lineation of the P- and Y- foliation. Lastly, although not strictly an inverse fabric samples A6 and A3 have the maximum and intermediate principal vectors of the AMS inverted from one another, 
suggesting that some of the same mechanisms for inverse fabrics found in other places operated within the Death Valley fault rocks [Rochette et al., 1999].

[39] There are therefore some systematic differences and similarities between the AMS and SPO of the Death Valley fault rocks. The differences between the AMS and SPO vectors is due to either: (1) a different response of magnetic grains to the kinematics of deformation, (2) the AMS not being a direct measure of the shape-preferred orientation of magnetic particles, or (3) the magnetic carriers having a different strain history than the clasts that define SPO such as is the case if the magnetic carriers are younger than the inherited clasts. As explained below, we favor a kinematic explanation for the differences between the AMS and SPO, underscoring the utility of each in understanding the deformational history of the Death Valley detachments.

\section{Source of AMS}

[40] The most difficult aspect of interpreting the significance of AMS is that the magnetic carriers within the mineralogy of a rock are not initially known. In the following few paragraphs, we present data from a variety of methods in an effort to determine the magnetic carriers in the fault rocks. We restrict the magnetic analyses to a few representative samples and leave for a future effort an investigation of high-temperature magnetic properties of the samples.

[41] There are several low-temperature transitions in the magnetic susceptibility that are indicative of the magnetic carriers within a sample. Characteristic low-T transitions include the Verwey transition at $120 \mathrm{~K}$ for magnetite, and the Morin transition at $-15^{\circ} \mathrm{C}$ for hematite [Dunlop and Özdemir, 1997]. Paramagnetic minerals, such as clay minerals, follow the Curie-Weiss law wherein MS varies as a function of $1 / \mathrm{T}$ (Figure 8). Therefore if the low-T data from the fault rock samples fit a $1 / T$ curve well, the dominant carrier of MS are probably clay minerals that are volumetrically significant in the fault rock samples. A lack of such $1 / T$ variation of MS with temperature would indicate that the MS is carried by either ferrimagnetic (magnetite) and/or diamagnetic (calcite, quartz) phases.

[42] All of the samples have a positive MS, ruling out the possibility that the carbonate and quartz in the samples are the dominant MS carriers (Figure 8). Many samples have a noticable increase in MS between 120 and 130K (Figures 8a and $8 \mathrm{~b}$ ), consistent with the Verwey transition. In some of these samples the only change in MS with T is the Verwey transition, indicating that magnetite is the dominant carrier of MS. Other samples (Figure 8c) have MS that is best fit by a $1 / \mathrm{T}$ variation, indicating that paramagnetic minerals are the dominant carriers of MS. A few samples have difficult to interpret low-T MS data wherein no Verwey transition is evident, but the change in MS with $\mathrm{T}$ does not fit a $1 / \mathrm{T}$ variation (Figures $8 \mathrm{~d}-8 \mathrm{f}$ ). It is possible that either oxidized minerals such as maghemite [Senanayake and McElhinny, 1981], or ultra-fine superparamagnetic minerals may be present in such samples.

[43] We found no clear relationship between the carrier of MS and fault rock unit. Samples of foliated breccia had either ferrimagnetic, or paramagnetic MS. Samples from clay and granular gouges all have ferrimagnetic MS, with
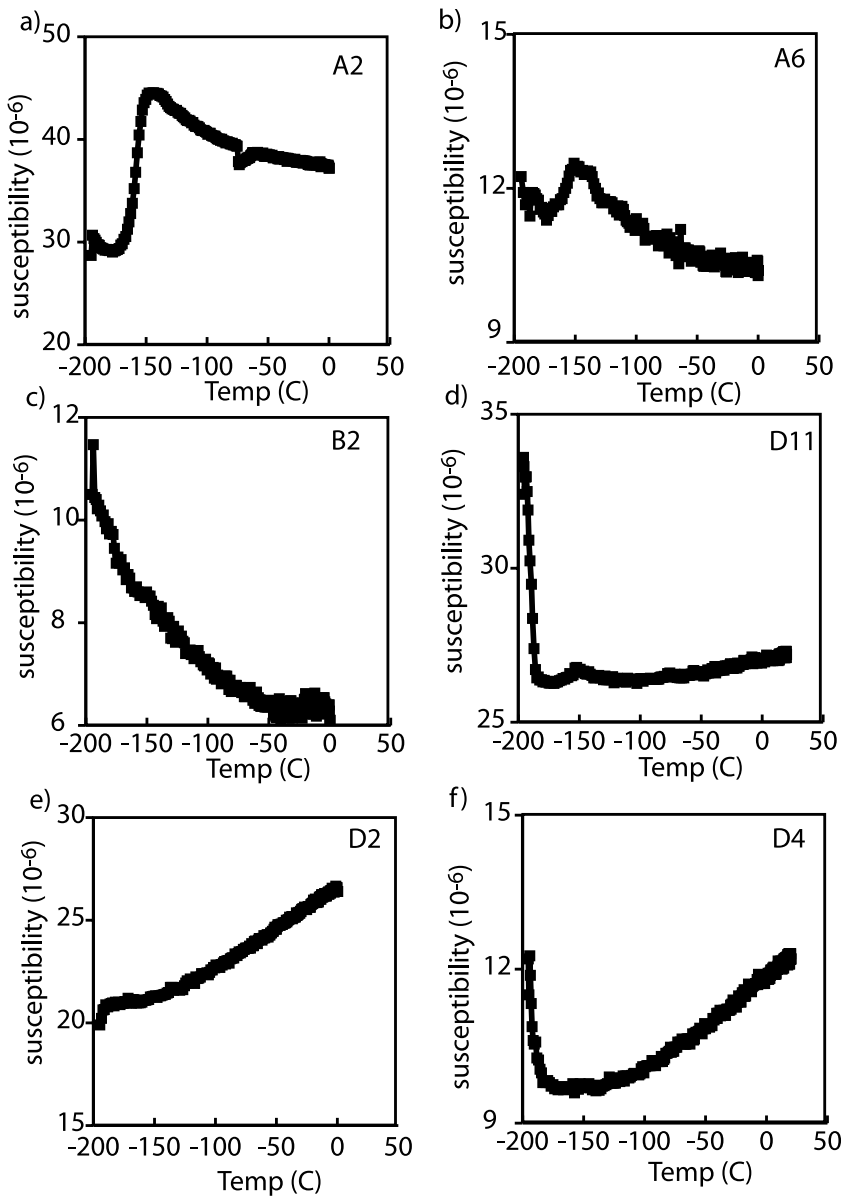

Figure 8. Representative results of the low-temperature experiments on the fault rocks. (a) a typical spectrum for the samples from Copper Canyon that we interpret to signify a magnetite-controlled AMS. (b) A6 has a weak Verwey transition suggesting that the magnetite has an ultra-fine grain size, or that oxidized phases such maghemite are important to carriers of MS. (c) A spectrum for sample B2 is best-explained by $1 / \mathrm{T}$ behavior due to paramagnetic minerals, such as clay minerals. (d, e, f) The Badwater clay gouges have a weak to pronounced drop in MS between $-200^{\circ} \mathrm{C}$ and $-150^{\circ} \mathrm{C}$, and a consistent increase in MS from -150 to $0^{\circ} \mathrm{C}$ suggesting that a mixture of paramagnetic clay minerals and maghemite and/or ultrafine (perhaps superparamagnetic) magnetite is the carrier of the MS.

some having pronounced transitions indicative of magnetite, while others do not have a clear Verwey transition.

[44] To further characterize the magnetic properties and magnetic fabrics in these samples, partial anhysteretic remanent magnetization (pARM) and anisotropy of pARM experiments [Jackson, 1991] were performed on selected samples from each lithology. The method is advantageous in that only magnetite fabrics are measured, and grain-size sub-populations as identified by pARM can also be separately measured, both of which minimizes the complications of fabric interpretation by isolating a single carrier of magnetization.

[45] The pARM results (Figure 9) have pronounced peaks that occur between 10 and $50 \mathrm{mT}$, which are consistent with 

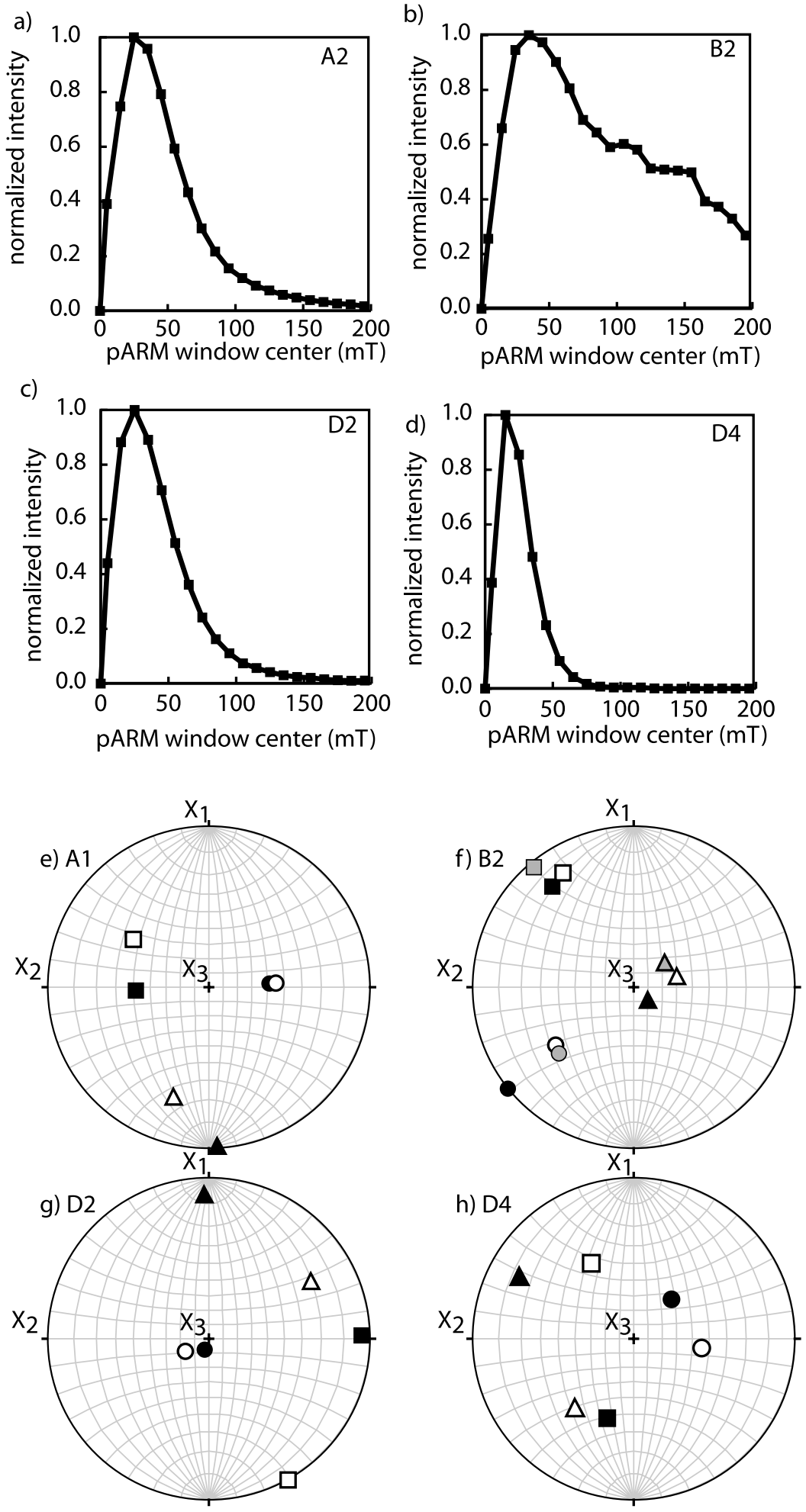

Figure 9. pARM/ApARM Representative pARM curves from the fault rocks. For all curves, the center of the $10-\mathrm{mT}$ wide pARM window is plotted versus normalized magnetization. The Copper canyon samples (a) have a single pARM peak at $25 \mathrm{mT}$, that we interpret to signify MD and PSD sized magnetite, the Mormon Point granular gouge (b) has a bi-modal pARM curve, with peaks at 50 and 100$150 \mathrm{mT}$ that indicate finer-grained magnetite, and both Badwater clay gouge (c, d) samples have single pARM peaks at 10 to $25 \mathrm{mT}$. (e-h) stereoplot of principal vectors of the pARM demonstrating nearcoaxiality of the ApARM and AMS. The symbolic convention is the same as for Figures 6 and 7 with open symbols the axes for AMS and solid or gray symbols the axes for ApARM. 
Table 4. A pARM Versus AMS for UW Fault Rocks ${ }^{\mathrm{a}}$

\begin{tabular}{|c|c|c|c|c|c|c|c|}
\hline Sample & pARM & $\begin{array}{c}\mathrm{D} \\
\max \end{array}$ & $\begin{array}{c}\mathrm{I} \\
\max \\
\end{array}$ & $\begin{array}{l}\mathrm{D} \\
\text { int }\end{array}$ & $\begin{array}{c}\text { I } \\
\text { int } \\
\end{array}$ & $\begin{array}{c}\mathrm{D} \\
\min \end{array}$ & $\begin{array}{c}\mathrm{I} \\
\mathrm{min} \\
\end{array}$ \\
\hline A1: AMS, c & & 267 & 41 & 177 & 00 & 87 & 49 \\
\hline A1: ApARM, cb & $100 \mathrm{mT}, 60-10 \mathrm{mT}$ & 302 & 39 & 197 & 18 & 87 & 45 \\
\hline B2: AMS, c & & 321 & 14 & 231 & 00 & 141 & 76 \\
\hline B2: ApARM, cb & $100 \mathrm{mT}, 60-10 \mathrm{mT}$ & 329 & 11 & 233 & 28 & 78 & 59 \\
\hline B2: ApARM2, cb & $200 \mathrm{mT}, 160-100 \mathrm{mT}$ & 320 & 2 & 230 & 27 & 54 & 63 \\
\hline D2: AMS, c & & 89 & 3 & 358 & 7 & 202 & 82 \\
\hline D2: ApARM, cb & $100 \mathrm{mT}, 60-10 \mathrm{mT}$ & 151 & 0 & 61 & 19 & 241 & 71 \\
\hline D4: AMS, c & & 199 & 35 & 298 & 12 & 44 & 53 \\
\hline D4: ApARM, cb & $100 \mathrm{mT}, 35-5 \mathrm{mT}$ & 330 & 32 & 219 & 30 & 97 & 43 \\
\hline
\end{tabular}

${ }^{a}$ AMS, Anisotropy of Magnetic Susceptibility from Kappabridge; Demag, AF Demagnetization level for pARM; pARM, partial Anhysteretic Remanent Magnetization window utilized for ApARM; ApARM, Anisotropy of partial Anhysteretic Remanent Magnetization calculated with k15 s.exe by L. Tauxe; c, core coordinates; cb, core coordinates, processed with initial demag before all 18 positions.

multidomain (MD) to pseudo-single-domain (PSD) magnetite [Jackson, 1991]. Sample B2 (Figure 9b) has notably higher coercivities, with a break in the pARM intensity between 100 and $150 \mathrm{mT}$. On the basis of the pARM measurements, the ApARM experiments for samples A1, $\mathrm{B} 2$, and $\mathrm{D} 2$ used a window from 10 to $60 \mathrm{mT}$ for the pARM, sample D4 used a window from 5 to $35 \mathrm{mT}$, and an additional window between 100 and $160 \mathrm{mT}$ was also selected for sample B2 to measure the fabric of the high coercivity fraction. The ApARM experiments revealed that, with one exception, the AMS and ApARM fabrics are essentially coaxial (Figures 9e-9h, Table 4). The exception is sample D4, which has a ApARM fabric that has its minimum pARM axis rotated approximately $45^{\circ}$ degrees clockwise from the AMS $\mathrm{k}_{3}$ axis, and a maximum (intermediate) pARM axis that is adjacent to the AMS $\mathrm{k}_{2}\left(\mathrm{k}_{1}\right)$ axis. This may indicate that the AMS of sample D4 is a composite fabric, of either two "normal" AMS sub-fabrics, or includes an "inverse" AMS sub-fabric.

[46] The most important conclusion in this context is that the low-T MS experiments, measurement of ApARM, compositional analyses, and microscopy collectively support the hypothesis that the dominant magnetic carriers in the Death Valley fault rock are not the large grains used to measure the SPO. Rather, the magnetic carriers are fine (micron-scale), and ultra-fine (micron-to-nanometer-scale), grains found in the matrix. However, determining what produces the anisotropy of the magnetic susceptibility poses an increased challenge. For single grains of paramagnetic phyllosilicates and clay minerals, the AMS is produced by a crystallographic preferred orientation (CPO) [Nye, 1985]. For single grains of magnetite, AMS is due to shape and not crystallographic orientation, and therefore a population of magnetite grains will produce an AMS that is directly proportional to the SPO of magnetite [Richter, 1991].

[47] The magnetic mineralogy contains mixtures of magnetite and related oxidized forms in an aggregate of clays and clay-sized minerals. Although the relationship between coercivity and grain shape can be complex for such oxidized magnetic phases [Kletetschka et al., 2000; Itoh and Sugimoto, 2003], we propose that the principal vectors of the AMS approximately track a shape-preferred orientation of ultra-fine minerals. Assuming that phyllosilicates and clay minerals attain a shape preferred orientation via paral- lelism of [001] planes [Oertel, 1985], then the CPO and SPO of phyllosilicates will be comparable. Given the observations of the close physical association of oxides and clays (Figure 3), it further stands to reason that the aggregate of "matrix" minerals produces a bulk-rock AMS that approximates the shape-controlled fabric of these grains. Lastly, there appears to be at least some magnetite in the fault rocks for which grain-shape largely controls the AMS. Therefore while there may be some deviation between the SPO of the "matrix" minerals and the orientation of the AMS axes, we propose that AMS at least closely tracks the "matrix" SPO.

\section{One Model for Fabric Development}

[48] The approximation of the SPO and AMS as measuring the orientation of rotated particles in a strained shear zone opens up the possibility of using established kinematic models for understanding the strain history of the fault rock. The deformation within the Black Mountain detachments has been previously approximated by simple shear [Cowan et al., 2003], and general shear at steady state and constant volume [Cladouhos, 1999b]. However, prolate AMS fabrics and some SPO fabrics are characterized by lineations in $b$, parallel to the strike direction $\left(\mathrm{X}_{1}\right)$. Furthermore, there are some similarities to inverse AMS fabrics in the Death Valley fault rocks. Lastly, AMS and SPO fabric elements at an angle to $X_{1}$ and $X_{2}$ and the principal vectors of AMS and SPO are at an angle to one another for many samples. A kinematic model that can accommodate the complex strain history of fabric development is therefore proposed for the Death Valley fault rocks.

[49] The most thorough formulation of a kinematic model for AMS development invokes transpression to explain the orientation of linear fabric elements [Ježek and Hrouda, 2002]. Changes in width of the shear zone, the introduction or expulsion of material from the shear zone and partitioning of strain onto discrete slip planes are not considered in the solution. We assume that the AMS in most samples from the Black Mountain detachments is produced by the SPO of "magnetic" minerals (be they paramagnetic clays, superparamagnetic oxides, or ferrimagnetic oxides). Although, as discussed in a previous paragraph, this is undoubtedly an oversimplification of the AMS, the theory exists [Richter, 1991] to support the abstraction of the AMS as SPO-vectors within a flow field.

[50] The relationship between shear strain and time is fully explained by Ježek and Hrouda [2002] and we give an abbreviated explanation here. The motion of any line or plane in a flow field can be modeled kinematically without regard to forces. The vector that represents the line or plane in the flow field is operated on by a tensor, $L_{i j}$, with components of strain rate $(\dot{\varepsilon})$. Components with $\mathrm{i} \neq \mathrm{j}$ correspond to non-pure-shear such that $\dot{\varepsilon}_{12}$ is the component of simple shear, equivalent to the shear strain $(\gamma)$ in $X_{2}-X_{3}$. These components can be related to the regional tectonics and wall rock reference frame of the shear zone via:

$$
\dot{\varepsilon}_{i=j}=\frac{v}{d} \sin \alpha ; \dot{\varepsilon}_{i \neq j}=\frac{v}{d} \cos \alpha
$$

where $\alpha$ is the angle between the motion of the wall rock, $v$ is the rate of change of thickness of the shear zone, and $d$ is 


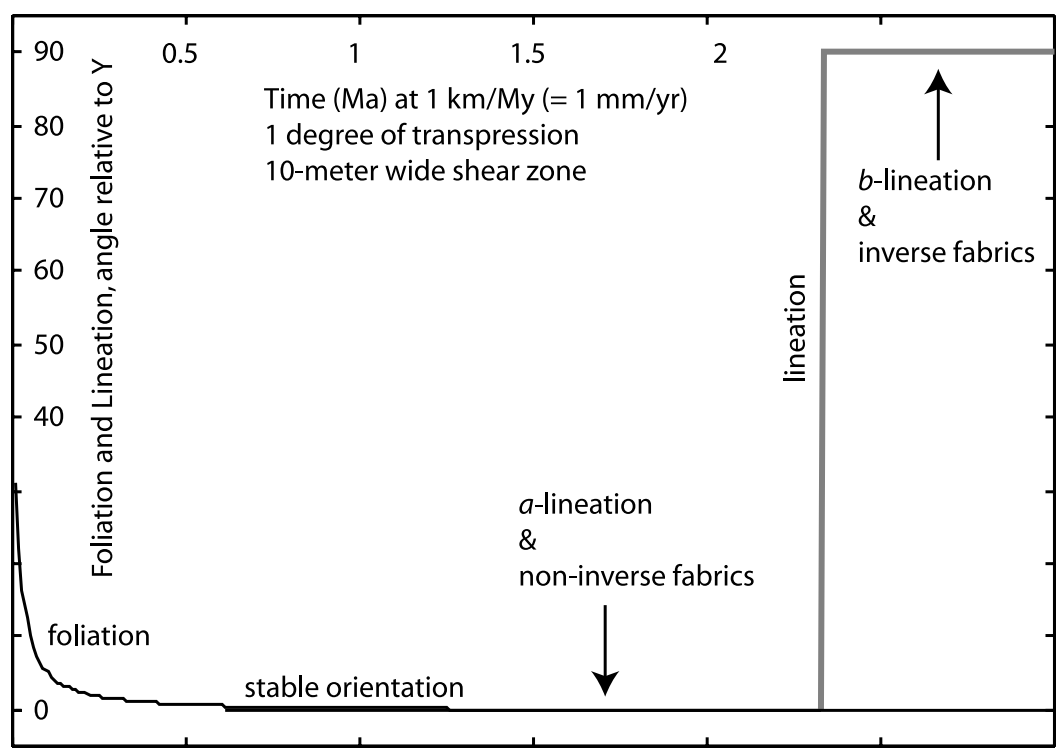

Figure 10. Orientation of fabric element versus shear strain (following Ježek and Hrouda [2002]) using representative values from the Death Valley detachments for strain rate $(1 \mathrm{~mm} / \mathrm{yr})$. Although idealized, the model explains the development of fabric parallel to the shear zone boundary (shear plane), and the development of fabric elements out of the plane of exposure, such as $b$-lineation and inverse AMS fabrics. By 0.5 Ma foliation develops an orientation parallel to the shear plane, consistent with the observation that late Quaternary sediment is incorporated in fabric in nature. Cladouhos [1999b] proposes a mechanism by which a stable foliation could develop in the P-orientation. After 2 Ma the lineation, approximated by prolate AMS ellipsoids, tracks the inversion of the maximum and intermediate vectors of the strain ellipsoids, resulting in $b$-lineation and/or inverse AMS fabrics.

the initial width of the shear zone. The $L_{i j}$ tensor produces an instantaneous increment of small displacement that can be related to a small increment of time, $t$, via:

$$
d(t+\Delta t)=I+L(t) \Delta t
$$

where $I$ is the identity matrix, and $d$ is the displacement. The displacement function operates on a vector $(x)$ :

$$
x(t+\Delta t)=x(t) d(t+\Delta t)
$$

[51] We approximate the dimensions of deformation within the detachments as $d=10 \mathrm{~m}$, and $v=1 \mathrm{~mm} / \mathrm{yr}$ $(=1 \mathrm{~km} / \mathrm{My})$, and $\alpha=1^{\circ}$ (nearly simple shear). A 10 -meter wide shear zone provides for minimum estimates of the amount of shear strain because deformation becomes quickly and strongly localized in the model for shear zones $<1 \mathrm{~m}$ wide. The solution of the kinematic analysis for these dimensions results in the foliation, such as defined by an oblate AMS or SPO, approaching a stable orientation at a low angle to the fault plane at relatively low shear strains of $\gamma>50$, after roughly 0.5 million years of strain accumulation (Figure 10).

[52] The kinematic model is consistent with the observation in the field of lenses of Quaternary-age sediment parallel to the foliation within the detachment shear zones [Cowan et al., 2003]. Furthermore, any prolate particle, or lineation, "flips" from $\mathrm{X}_{2}$-parallel, to $\mathrm{X}_{1}$-parallel or $\mathrm{X}_{3}$ parallel orientations. This is a natural consequence of the inversion of the principal axes of the finite strain ellipsoid with large transpressive strain [Tikoff and Teyssier, 1994]. The prolate fabrics that are parallel to $\mathrm{X}_{1}$ (lineation in $b$ ) or
$\mathrm{X}_{3}$ (inverse fabrics) therefore require $\gamma>250$, or $2.5 \mathrm{Ma}$ given millimeter per year strain rates. The estimate of the time-scale is consistent with the geologic observation that some of the fault rock is certainly older than $2.5 \mathrm{Ma}$ given early Pliocene sediment in the hanging wall of the detachments [Holm et al., 1994]. The multiple ages of, and the presence of newly grown minerals within, the fault rock implies a kinematic explanation for the divergence between AMS and SPO. Namely, if the SPO or AMS measure a younger population than the other, than they will be measuring a different increment of strain from one another, resulting in differing orientations of principal vectors.

\section{Discussion and Conclusions}

[53] An important conclusion from this study of the Death Valley fault rocks is that AMS and SPO are defined by meaningful vectors that can be used to evaluate the history of fault-rock deformation and kinematics of fault slip. For example, AMS and SPO fault planes in some samples indicates a modest pitch to the north on some segments of the detachments, consistent with partitioning of slip on segments that locally strike at an angle to the regional tectonic motion. The realization that AMS and SPO are measures of fabric elements that track the large-scale tectonics of the Death Valley detachments raises the questions of what, exactly, are AMS and SPO measuring, and what is their significance to the micromechanics of faulting.

[54] We interpret the AMS in the fault rocks to be produced by the preferred orientation of different and finer grains than those that define the SPO. There are important alternative interpretations of AMS that we briefly consider. 
Coseismic fault slip is thought to produce electromagnetic and thermal responses that can be preserved in the rock record [e.g., Enemoto and Zheng, 1998]. In the event that faulting produces frictional melts, the devitrification of the glassy product and/or melting dynamics can produce oxides that contribute to the AMS of fault rock [Fukuchi, 2003]. It is also possible that the neotectonic stress field (also responsible for the aforementioned electromagnetic responses) may have been recorded by AMS via magnetostriction effects in MD magnetite grains present in some of these fault rocks [Borradaile and Hamilton, 2004]. Furthermore, specific phases that may be present in the fault rocks (e.g., maghemite) probably have a different relationship between grain shape and AMS than magnetite, for example [Itoh and Sugimoto, 2003].

[55] We acknowledge the possible importance of transitions between, and AMS properties of, different paramagnetic, superparamagnetic, and ferrimagnetic minerals in the Death Valley fault rocks. Indeed, future research may recognize the geologic record of thermal and electromagnetic anomalies in the fault rock, but none has been found to date. However, many of the grains within the matrix of the fault rock demonstrably grew via waterrock reactions at relatively low temperatures and were subsequently rotated by distributed deformation. The aggregate of clay minerals and iron-bearing oxides produce an AMS that is most consistent with fabrics defined by shape-preferred orientations. We propose that any difference between the AMS and SPO of a single grain is outweighed by the AMS produced by the aggregate. Future findings bearing on the electromagnetic and thermal history of the Death Valley fault rocks will probably not affect our interpretation of the AMS and SPO as measuring grain orientations that develop during cataclastic and granular flow.

[56] Similarly, the micromechanics of gouge production and deformation have important alternative hypotheses. Some gouges are proposed to have developed as a direct consequence of the repeated passage of seismic rupture [Chester and Chester, 1998] or coseismic dispersive flow of particles [Otsuki et al., 2003]. Again, we contend that our proposed kinematic model of grain rotation over geologic time, whether coupled with seismic slip or not, best explains aspects of the observed fault-rock fabric. We note that the coseismic response of the Death Valley fault rock has not yet been properly evaluated [e.g., Cowan, 1999].

[57] Kinematic models, such as the one that we prefer, do not address forces or the relationship between stress and strain during the deformation of the material. However, there are assumptions about the rheology and mechanics of materials that are built into specific kinematic models. For example, the kinematic model of Ježek and Hrouda [2002] is rooted in the equations developed by Jeffery [1922] to describe the motion of particles within a medium that exerts no traction on the particles that rotated into their orientation. Our proposed explanation for the AMS and SPO holds that the development of fabric at the finest scales (i.e., in the "matrix" as measured by AMS) is compatible with the same kinematic evolution that produced preferred orientation in the larger scales (i.e., the "clasts" as measured by SPO). We hypothesize that the micromechanics of fault- rock deformation may include interesting particle interactions that, as an aggregate, may produce responses such as low static strength and stable dynamic sliding.

[58] Acknowledgments. We thank Darrel Cowan for overseeing Death Valley research at the University of Washington. We also thank David Veblen for the use of the facilities at Johns Hopkins University. Reviews by William MacDonald and Tatsuro Fukuchi greatly improved the manuscript. Reviews of an earlier draft by Keith Benn and Glen Wallace contributed greatly to the scientific direction of the study. Gary Petro provided the measurements of the pARM and low-T MS experiments. Hayman received partial support from Petroleum Research Fund administered by the American Chemical Society (to Darrel Cowan), the Krauss Crystallographic Research Fund of the American Mineralogical Society, and the Joe Vance award courtesy of University of Washington. Final drafting of the manuscript by Hayman was supported by NSF OCE0222154 (to J. Karson). Housen would like to acknowledge the support of NSF grant EAR-9727032 for the WWU cryogenic magnetometer.

\section{References}

Agterberg, F. P. (1974), Geomathematics, 596 pp., Elsevier Sci., New York. Axen, G. J. (1999), Low angle normal fault earthquakes and triggering, Geophys. Res. Lett., 26, 3693-3696.

Borradaile, G. J. (1991), Correlation of strain with anisotropy of magnetic susceptibility (AMS), Pure Appl. Geophys., 135, 15-29.

Borradaile, G. J., and T. Hamilton (2004), Magnetic fabrics may proxy as neotectonic stress trajectories, Polis rift, Cyprus, Tectonics, 23(1), TC1001, doi:10.1029/2002TC001434

Chester, F. M., and J. S. Chester (1998), Ultracataclasite structure and friction processes of the Punchbowl fault, San Andreas System, California, Tectonophysics, 295, 199-221.

Chester, F. M., and J. M. Logan (1987), Composite planar fabric of gouge from the Punchbowl fault, California, J. Struct. Geol., 9, 621-634.

Cladouhos, T. T. (1999a), Shape preferred orientations of survivor grains in fault gouge, J. Struct. Geol., 21, 419-436.

Cladouhos, T. T. (1999b), A kinematic model for deformation within brittle shear zones, J. Struct. Geol., 21, 437-448.

Cowan, D. S. (1999), Do faults preserve a record of seismic slip? A field geologist's opinion, J. Struct. Geol., 21, 995-1001.

Cowan, D. S., and M. T. Brandon (1994), A symmetry based method for kinematic analysis of large-slip brittle fault zones, Am. J. Sci., 294, 257306.

Cowan, D. S., T. T. Cladouhos, and J. Morgan (2003), Structural geology and kinematic history of rocks formed along low-angle normal faults, Death Valley, California, Geol. Soc. Am. Bull., 115, 1230-1248.

Drewes, H. (1963), Geology of the Funeral Peak Quadrangle, California, on the eastern flank of Death Valley, U.S. Geol. Surv. Prof. Pap. 413, 78 pp.

Dunlop, D. J., and O. Özdemir (1997), Rock Magnetism: Fundamentals and Frontiers, 573 pp., Cambridge Univ. Press, New York.

Enemoto, Y., and Z. Zheng (1998), Possible evidence of earthquake lightning accompanying the 1995 Kobe earthquake inferred from the Nojima fault gouge, Geophys. Res. Lett., 25, 2721-2724.

Fukuchi, T. (2003), Strong ferrimagnetic resonance signal and magnetic susceptibility of the Nojima pseudotachylyte in Japan and their implication for coseismic electromagnetic changes, J. Geophys. Res., 108(B6), 2312, doi:10.1029/2002JB002007.

Ghosh, S. K., and H. Ramberg (1976), Reorientation of inclusions by combination of pure shear and simple shear, Tectonophysics, 34, 1-70.

Hayman, N. W. (2000), Deformational-Authigenic process in the Death Valley detachments, Eos Trans. AGU, 81(48), Fall Meet. Suppl., Abstract F1134.

Hayman, N. W. (2003), Structure and petrology of gouge and breccia bearing shallow crustal shear zones of detachment faults in Death Valley, California, Ph.D. dissertation, 167 pp., Univ. of Wash., Seattle.

Hayman, N. W., J. R. Knott, D. S. Cowan, E. Nemser, and A. SarnaWojcicki (2003), Quaternary low-angle slip on detachment faults in Death Valley, California, Geology, 31, 343-346.

Holm, D. K., R. J. Fleck, and D. R. Lux (1994), The Death Valley Turtlebacks reinterpreted as Miocene-Pliocene folds of a major detachment surface, J. Geol., 102, 718-727.

Housen, B. A., C. Richter, and B. A. van der Pluijm (1993), Composite magnetic anisotropy fabrics: Experiments, numerical models, and implications for the quantification of rock fabrics, Tectonophysics, 220, 1-12.

Hrouda, F. (1982), Magnetic anisotropy and its application in Geology and Geophysics, Geophys. Surv., 5, 37-82.

Itoh, H., and T. Sugimoto (2003), Systematic control of size, shape, structure, and magnetic properties of uniform magnetite and maghemite particles, J. Colloid Interface Sci., 265, 283-295. 
Jackson, J. A., and N. J. White (1989), Normal faulting in the upper continental crust: Observations from regions of active extension, J. Struct. Geol., 11, 15-36.

Jackson, M. (1991), Anisotropy of magnetic remnance: A brief review of mineralogical sources, physical origins, and geological applications, and comparison with susceptibility anisotropy, Pure Appl. Geophys., $136,1-28$.

Jeffery, G. B. (1922), The motion of ellipsoidal particles immersed in a viscous fluid, Proc. R. Soc. London, Ser. A, 102, 161-179.

Ježek, J., and F. Hrouda (2002), Software for modeling the magnetic anisotropy of strained rocks, Comput. Geosci., 28, 1061-1068.

Jelinek, V. (1978), Statistical processing of anisotropy of magnetic susceptibility measured on groups of specimens, Stud. Geophys. Geod., 22, 5062.

Keener, C., L. F. Serpa, and T. L. Pavlis (1993), Faulting at Mormon Point, Death Valley, California: A low-angle normal fault cut by high-angle faults, Geology, 21, 327-330.

Kletetschka, G., P. J. Wasilewski, and P. T. Taylor (2000), Hematite vs magnetite as the signature for planetary magnetic anomalies?, Phys. Earth Planet. Inter., 119, 259-267.

Kodama, K. P., and W. W. Sun (1990), SEM and magnetic fabric study of a compacting sediment, Geophys. Res. Lett., 17, 795-798.

Linde, A. T., M. T. Gladwin, M. J. Johnston, R. L. Gwyther, and R. G. Bilham (1996), A slow earthquake sequence on the San Andreas fault, Nature, 383, 65-68.

Lister, G. S., and A. W. Snoke (1984), S-C mylonites, J. Struct. Geol., 6, $617-618$.

Logan, J. M., M. Friedman, N. Higgs, C. Dengo, and T. Shimanto (1979), Experimental studies of simulated gouge and their application to studies of natural fault zones, in Proceedings of Conference VIII on Analysis of Actual Fault Zones in Bedrock, U.S. Geol. Surv. Open File Rep., 791239.

March, A. (1932), Mathematische theorie der regelung nach der korngestalt bei affiner deformation, Zeit. Kristall., 81, 285-297.

Miller, M. G. (1996), Ductility in fault gouge from a normal fault system, Death Valley, California: A mechanism for fault-zone strengthening and relevance to paleoseismicity, Geology, 24, 603-606.

Miller, M. M., D. J. Johnson, T. H. Dixon, and R. K. Dokka (2001), Refined kinematics of the Eastern California shear zone from GPS observations, 1993-1998, J. Geophys. Res., 106, 2245-2263.

Morgan, J. K. (1999), Numerical simulations of granular shear zones using the distinct element method: 2. Effects of particle size distribution and interparticle friction on mechanical behavior, J. Geophys. Res., 104, $2721-2732$

Morgan, J. K., and M. S. Boettcher (1999), Numerical simulations of granular shear zones using the distinct element method; 1, Shear zone kinematics and the micromechanics of localization, J. Geophys. Res. 104, 2703-2719.

Morgan, J. K., T. T. Cladouhos, K. M. Scharer, D. S. Cowan, and P. J. Vrolijk (1996), Fractal particle size distributions in Death Valley fault zones; controls on mechanics and kinematics of fault rocks, Eos Trans. $A G U, 77(46)$, Fall Meet. Suppl., F717.

Nye, J. F. (1985), Physical Properties of Crystals, 329 pp., Oxford Sci. Publ., New York.

Oertel, G. (1985), Reorientation due to grain shape, in Preferred Orientation in Deformed Metals and Rocks: An Introduction to Texture Analysis, edited by H.-R. Wenk, pp. 259-266, Academic, San Diego, Calif.
Otsuki, K., N. Monzawa, and T. Nagase (2003), Fluidization and melting of fault gouge during seismic slip: Identification in the Nojima fault zone and implications for focal earthquake mechanisms, J. Geophys. Res., 108(B4), 2192, doi:10.1029/2001JB001711.

Richter, C. (1991), Particle motion and the modeling of strain response in magnetic fabrics, Geophys. J. Inter., 110, 451-464.

Rochette, P., C. Aubourg, and M. Perrin (1999), Is this magnetic fabric normal? A review and case studies in volcanic formations, Tectonophysics, 307, 219-234.

Rutter, E. H., R. H. Maddock, and S. H. Hall (1986), Comparative microstructures of natural and experimentally produced clay-bearing fault gouges, Pure Appl. Geophys., 124, 3-30.

Saffer, D. M., and C. Marone (2004), Comparison of smectite- and illiterich gouge frictional properties: Application to the updip limit of the seismogenic zone along subduction megathrusts, Earth Planet. Sci. Lett., 215, 219-235.

Sander, B. (1930), Gefugekene der Gesteine, 352 pp., Springer-Verlag, New York.

Senanayake, W. E., and M. W. McElhinny (1981), Hysteresis and susceptibility characteristics of magnetite and titanomagnetites: Interpretation of results from basaltic rocks, Phys. Earth Planet. Inter., 26, 47-53.

Sibson, R. H. (1977), Fault rocks and fault mechanisms, J. Geol. Soc. London, 133, 191-213.

Snoke, A. W., and J. Tullis (1998), An overview of fault rocks, in FaultRelated Rocks: A Photographic Atlas, edited by A. W. Tullis and V. R. Todd, pp. 3-18, Princeton Univ. Press, Princeton, N. J.

Tarling, D. H., and F. Hrouda (1993), The Magnetic Anisotropy of Rocks, 217 pp., Chapman and Hall, New York.

Tikoff, B., and C. Teyssier (1994), Strain modeling of displacement-field partitioning in transpressional orogens, J. Struct. Geol., 16, 15751588 .

Twiss, R. J., and E. M. Moores (1992), Structural Geology, W. H. Freeman, New York.

Varga, R. J. (1983), A statistical study of phenocryst orientation fabrics in a dacite ignimbrite, J. Volcanol. Geotherm. Res., 19, 37-43.

Vrolijk, P., and B. A. van der Pluijm (1999), Clay gouge, J. Struct. Geol., $21,1039-1048$

Vrolijk, P. J., T. T. Cladouhos, D. S. Cowan, and J. Morgan (1997), Importance of alteration reactions for the Death Valley fault zone, Abstracts Prog. Geol. Soc. Am., 29, 258.

Wright, L. A., and B. W. Troxel (1984), Geology of the northern half of the Confidence Hills 15-minute Quadrangle, Death Valley region, eastern California; the area of the Amargosa chaos, Map Sheet 34, Calif. Div. of Mines and Geol., Sacramento, Calif.

T. T. Cladouhos, WebPE, Inc., 1932 First Ave., Suite 100, Seattle, WA 98101, USA. (tcladouhos@webpe.com)

N. W. Hayman, Division of Earth and Ocean Science, Box 90227, 103 Old Chemistry Building, Duke University, Durham, NC 27708-0230, USA. (hayman@duke.edu)

B. A. Housen, Geology Department, Western Washington University, 516 High St., Bellingham, WA 98225-9080, USA. (bernieh@cc.wwu.edu)

K. Livi, Department of Earth and Planetary Sciences, 3400 N. Charles St., Johns Hopkins University, Baltimore, MD 21218, USA. (klivi@jhu. edu) 